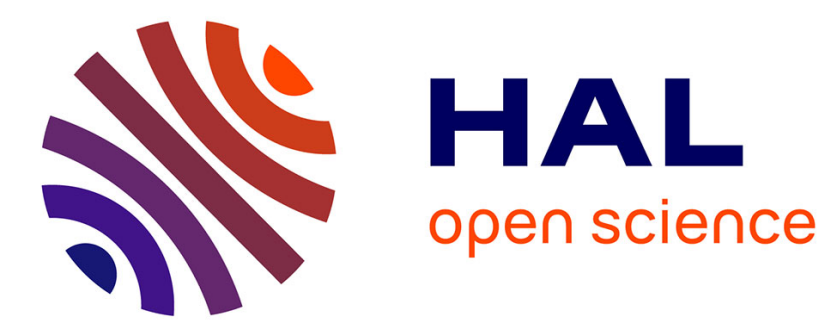

\title{
On the accuracy of intermolecular interactions and charge transfer: the case of TTF-CA
}

Pilar García, Slimane Dahaoui, Claudine Katan, Mohamed Souhassou, Claude Lecomte

\section{- To cite this version:}

Pilar García, Slimane Dahaoui, Claudine Katan, Mohamed Souhassou, Claude Lecomte. On the accuracy of intermolecular interactions and charge transfer: the case of TTF-CA. Faraday Discussions, 2007, 135, pp.217-235. 10.1039/B606642A . hal-01416922

HAL Id: hal-01416922

https://hal-univ-rennes1.archives-ouvertes.fr/hal-01416922

Submitted on 15 Dec 2016

HAL is a multi-disciplinary open access archive for the deposit and dissemination of scientific research documents, whether they are published or not. The documents may come from teaching and research institutions in France or abroad, or from public or private research centers.
L'archive ouverte pluridisciplinaire HAL, est destinée au dépôt et à la diffusion de documents scientifiques de niveau recherche, publiés ou non, émanant des établissements d'enseignement et de recherche français ou étrangers, des laboratoires publics ou privés. 


\title{
On the accuracy of intermolecular interactions and charge transfer: the case of TTF-CA
}

\author{
Pilar García $^{a}$, Slimane Dahaoui ${ }^{a}$, Claudine Katan ${ }^{b}$, Mohamed Souhassou $^{a}$ and Claude \\ Lecomte $^{a} \dagger$
}

High-resolution X-ray diffraction experiments and state of the art density functional theory calculations have been performed. The validity of the atoms in molecules approach is tested for the neutral-ionic transition of TTF-CA which involves a transfer of less than one electron between the donor and acceptor molecules. Foremost, crystallographical data have been reassessed along the temperature-induced neutralionic phase transition undergone by this charge transfer complex. Based on accurate X-ray structures at 105 and $15 \mathrm{~K}$, topological analysis of both DFT and the experimental multipolar electron densities allowed detailed characterization of intra- and interstack intermolecular interactions. Direct quantification of the intermolecular charge transfer and the dipole moment are discussed.

\section{Introduction}

Molecular and hybrid organic-inorganic materials will gradually replace the harder inorganic materials. The efficiency of some of these materials is linked to the cooperativity concept which is widely used among the molecular materials community. However, cooperativity is still not understood on physical and chemical grounds; it needs thorough investigations of intermolecular interactions (hydrogen bonds, van der Waals contacts, hydrophobicity, charge transfer...) which is a very big challenge for both experimental and theoretical methods. This paper will concentrate on the characterization of intermolecular contacs and on the estimation of the molecular and atomic charges. Intermolecular interactions are usually experimentally characterized by crystallographic or Raman-IR methods: conventional crystallography gives interatomic distances which should be compared to the sum of the so called "ionic" or "van der Waals" radii which are defined from statistical analysis of experimental interatomic distances. IR or Raman methods correlate intermolecular interactions to the variation of typical phonon or molecular group modes but the assumption are also empirical and only qualitative. Therefore one has to go a step further by modelling accurately the charge density in the intermolecular regions: this will give a direct estimation of the molecular charges. This can be achieved either by theoretical methods (Ab initio, DFT) or/and accurate high resolution crystallography. ${ }^{1,2}$ Once a model of the continuous charge density is obtained, then a method has to be chosen for analysing the interactions and accurately estimate the atomic group or molecular charges. This method has to be used on experimental and theoretical charge densities.

The charge concept of an atom is not based on physically measurable quantities because it is subjected to atom partitioning. In fact, it is impossible to determine unambiguously the atomic boundary inside which an atomic charge is located: atomic charges depend on the form and the size of the integration volume and on the atomic orbitals used (Ab Initio Methods). Hirshfeld has proposed in $1977^{3}$ the stockholder scheme using an atomic weighting function

$$
w_{j}(\vec{r})=\rho_{j}^{s p h}(r) / \rho_{\text {pro }}^{s p h}(r)
$$

where $\rho^{\text {sph }}$ is the electron density of the independent atom $\left(\rho_{j}^{s p h}\right)$ or of the promolecule $\left(\rho_{\text {pro }}^{s p h}\right)$. When multiplied by the modelled density $\rho(\vec{r})$ the function gives an estimation of the charge density of the $\mathrm{j}^{\text {th }}$ atom of the unit cell

$$
\rho_{j}(\vec{r})=\rho(\vec{r}) \cdot w_{j}(\vec{r})
$$

The limiting atomic volume is therefore given by a threshold of $\mathrm{w}_{\mathrm{j}}$. Such atoms have therefore some overlap. Coppens ${ }^{4}$ has also proposed a method based on the Wigner-Seitz method which defines an atomic polyhedron which boundaries are defined by

$$
\left(\vec{r}-\vec{r}_{A}\right) \frac{\vec{R}_{A B}}{R_{A}}=\left(\vec{r}-\vec{r}_{B}\right) \frac{\vec{R}_{A B}}{R_{B}}
$$

$\mathrm{R}_{\mathrm{AB}}$ being the internuclear distance and $\mathrm{R}_{\mathrm{A}}$ and $\mathrm{R}_{\mathrm{B}}$ are "a priori" atomic radii. This method which was used to estimate

\footnotetext{
${ }^{a}$ Laboratoire de Cristallographie et Modélisation des Matériaux Minéraux et Biologiques LCM ${ }^{3}$ B CNRS UMR 7036.Université Henri Poincaré, Nancy 1, Faculté des Sciences, BP 239, 54506 Vandoeuvre- lès-Nancy Cedex (France).

${ }^{b}$ Synthèse et ElectroSynthèse Organiques, CNRS UMR6510, Université de Rennes 1, Campus de Beaulieu, Bât. 10A,Case 1003, 35402 Rennes

$\dagger$ Author to whom correspondece should be adressed. E-mail:Claude.Lecomte@lcm3b.uhp-nancy.fr
} 
the charge transfer in the TTF-TCNQ material relies on the van der Waals radii. In conclusion all these partitioning applied to both experimental and theoretical models are based on "a priori" assumptions. On the other hand, Mulliken partitioning ${ }^{5}$ is only used with theoretical electron density whereas the $\kappa_{-} \mathrm{P}_{\mathrm{v}}$ refinement method ${ }^{6}$ is widely used by Xray diffractionists only : it assumes an expanded/contracted spherical pseudoatom density

$$
\rho_{j}(r)=\rho_{j}^{\text {core }}(r)+P_{j}^{v a l} \kappa_{j}^{3} \rho_{j}^{v a l}\left(\kappa_{j} r\right)
$$

where $\rho^{\text {core }}$ and $\rho^{\text {val }}$ are HF electron densities of the free atoms. Other methods to estimate charges are potential fitted charges ${ }^{7,8}$. We have shown that these fitted charges are very close to those obtained directly by $\kappa-\mathrm{P}_{\mathrm{v}}$ refinement.

Bader ${ }^{9}$ proposed a topological analysis of the total electron density based on quantum mechanics: the whole molecular system in the crystal is represented by a sum of non overlapping atomic basins: their boundary surface is limited by zero flux surfaces

$$
\nabla \rho(\vec{r}) \cdot n(\vec{r})=0
$$

Integration of charge, dipole and multipole moments inside the atomic basins can be performed. This last method can be applied to both experimental and theoretical data and has the advantage to characterise intermolecular interactions ${ }^{10}$ by bond paths and charge density at the critical points $(\vec{\nabla} \rho(\vec{r})=0)$.

The present discussion proposes to address the accuracy of such an approach on the basis of up to date experimental and theoretical results obtained for a model compound. The tetrathiafulvalene-p-chloranil (TTF-CA; $\mathrm{C}_{6} \mathrm{~S}_{4} \mathrm{H}_{4} \cdot \mathrm{C}_{6} \mathrm{Cl}_{4} \mathrm{O}_{2}$ ) was chosen because it shows small charge transfer (less than 1e) via intermolecular interactions that depends on various thermodynamic parameters $(\mathrm{T}, \mathrm{P}, h v)$. The TTF-CA complex is built from donor $(\mathrm{D}=\mathrm{TTF})$ and acceptor $(\mathrm{A}=\mathrm{CA})-\mathrm{D}-\mathrm{A}-\mathrm{D}-\mathrm{A}-\mathrm{D}-\mathrm{A}$ stacks and undergoes a first-order neutral-ionic phase transition (NIT) under temperature variation at a critical temperature of about $80 \mathrm{~K}^{11,12}$ as well as under pressure variation at a critical pressure of about 11 kbar. $^{12,13,14} \mathrm{~N}$ to I or I to $\mathrm{N}$ conversion can also be induced by photoirradiation as was shown by Koshihara et al. ${ }^{15}$ allowing for time-resolved crystallography of such a transformation at the picosecond time scale. ${ }^{16}$

According to vibrational spectroscopy and absorption spectra experiments ${ }^{17}$, the charge transfer (CT) $\mathrm{q}_{\mathrm{CT}}$ has been estimated to increase from $0.3 \mathrm{e}$ in the $\mathrm{N}$ phase to 0.7 in the I phase. It has been shown that this NIT comes along with a structural phase transition characterized by the loss of inversion symmetry (P21/n to Pn space group ) and a dimerization along the stacking axis. ${ }^{18}$

Before getting onto the main purpose of this work, crystallographical data need to be reassessed along the temperature-induced neutral-ionic phase transition undergone by TTF-CA, to ensure appropriate starting point. Based on the outcoming X-ray structures obtained at 105 and $15 \mathrm{~K}$, intra- and intermolecular interactions are discussed on the ground of the topology of both experimental and theoretical total electron densities . Corresponding D (TTF) and A (CA) single crystals have also been investigated to provide benchmarks. Quantification of the intermolecular interaction, charge transfer and the dipole moments through the topological analysis of the electron density will be discussed.

\section{Experimental section}

\subsection{Experimental details}

TTF and CA powders were purchased from Lancaster and purified. Single crystals of TTF were obtained by sublimation method. Chloranil crystals were obtained in acetonitrile solution. After a few days of slow evaporation, prismatic yellow single crystals appear in the solution. Single crystals of the TTF-CA complex were grown by sublimation of the component materials in a vacuum-sealed Pyrex glass tube, which was placed at $79{ }^{\circ} \mathrm{C}$ in an electric furnace for several days. Dark prismatic-like crystals were obtained.

The temperature evolution of the unit cell parameters was studied using a home-made helium bath cryostat ${ }^{19}$ specially designed for a four-circle diffractometer equipped with a 2D detector. The sample is mounted on a two-circle goniostat placed in the Helium tail of the cryostat. This goniostat is magnetically coupled to a master magnet fit on the arm of the diffractometer which allows the orientation of the sample inside the cryostat. The cell parameters were determined by the analysis of a set of 84 and 42 images, when cooling and warming, respectively, repeated from $110 \mathrm{~K}$ to $50 \mathrm{~K}$, with an accuracy of $0.02 \mathrm{~K}$.

For the structures and charge density determinations, three-dimensional diffraction data were collected on Enraf-Nonius Kappa and Oxford-Xcalibur-Sapphire2 CCD-based diffractometers with $\mathrm{MoK} \alpha$ radiation and a nominal crystal-to-detector distance of $40 \mathrm{~mm}$. The crystal was cooled from room temperature to $105 \mathrm{~K}$ with an Oxford Cryosystems $\mathrm{N}_{2}$ open flow cryostat ${ }^{20}$ and to $15 \mathrm{~K}$ with an Oxford Diffraction Helijet open-flow He gas cryosystem. 
Integration of frames and data reduction were performed with DENZO ${ }^{21}$ and CrysAlis Red ${ }^{22}$ programs. The multiple integrated reflections were averaged using SORTAV ${ }^{23}$ adapted to area detector data. Internal agreement factors for all data are given in Table 1 . Only reflections having $\mathrm{I} \geq 3 \sigma(\mathrm{I})$ were used in the structure and electron density least-squares refinements.

At $105 \mathrm{~K}$, TTF-CA crystallizes in the monoclinic system, space group $\mathrm{P} 2{ }_{1} / \mathrm{n}$ (systematic absences: $\mathrm{h} 01, \mathrm{~h}+1 \neq 2 \mathrm{n} ; 0 \mathrm{k} 0, \mathrm{k} \neq 2 \mathrm{n}$ ). At $15 \mathrm{~K}$, diffraction intensities of $(0 \mathrm{k} 0)$ with $\mathrm{k}=2 \mathrm{n}+1$ do exist, while reflections (h0l) with $\mathrm{h}+\mathrm{l}=2 \mathrm{n}+1$ remain systematically absent in agreement with the loss of the $2_{1}$ screw axis, the space group of the ionic phase is then Pn. In order to compare both structures, the coordinates $\mathrm{x}$ and $\mathrm{z}$ of the C119 atom were fixed at high temperature (HT) structure values and only the $\mathrm{y}$ coordinate was refined for the low temperature (LT) data. Sorted data were merged in the $\mathrm{m}$ point group, and anomalous dispersion corrections were performed as described in Souhassou et al. ${ }^{24}$ Experimental details are reported in Table 1.

Molecular structures of TTF-CA were solved by direct methods and subsequent Fourier analysis, then, refined, with a fullmatrix least-squares refinement (independent atom model IAM, SHELXL-97) ${ }^{25}$ Hydrogen atoms were first constrained to positions contained from neutron diffraction experiments. ${ }^{18}$ The final refined parameters were imported into the MOLLY program to model the aspherical electron density. ${ }^{26}$ After convergence of the multipolar refinement, $\mathrm{H}$ atoms were allowed to relax as their aspherical electron density features are taken into account in the multipolar refinement, leading to unbiased $\mathrm{H}$ positions. Recently we have shown that this method gives best $\mathrm{C}-\mathrm{H}$ bond distances close within 0.03 A to distances usually found from neutron diffraction. ${ }^{27}$

It is very important to note that, although the molecules do not lie anymore on inversion centres in the LT phase, molecular geometries are only slightly deformed, remaining almost centrosymmetric as will be discussed later. This feature induces strong correlations between charge density parameters of pseudo symmetry related atoms. In order to avoid these correlations, the following approach was carried out: first all atoms positions and thermal parameters were refined together without any constraints or restraints until convergence, and then the multipole parameters $\left(\right.$ all $\kappa, \mathrm{P}_{\mathrm{v}}$ and $\left.\mathrm{P}_{\operatorname{lm}}\right)$ of atoms related by an inversion centre in the $\mathrm{N}$ phase were constrained to be equal. This procedure leads to excellent statistical indexes as $\mathrm{R}$ factors are smaller than $1.3 \%$. The maxima and the minima in the residual density maps do not exceed $0.10 \mathrm{e} \AA^{-3}$. The estimate of the average error in the experimental electron density maps is $0.05{\mathrm{e} . \AA^{-3}}^{-3}$, as calculated by ${ }^{28,29}$

$$
\left\langle\sigma_{r e s}^{2}\right\rangle^{1 / 2}=\frac{2}{V}\left[\sum_{H}\left(K^{-1}\left|F_{o b s}\right|-\left|F_{m}\right|\right)^{2}\right]^{1 / 2}
$$

This error is largely smaller in the intermolecular region.

Aspherical modelling of the experimental X-ray structure factors provides the total electron density distribution $\rho(\mathbf{r})$ which is the main observable in the "Quantum Theory of Atoms in Molecules" developed by Bader. ${ }^{30}$ The topology of the total charge density allows a unique partition of the density into atomic contributions, by defining atomic basin as the volume limited by zero electron density gradient flux. Topological properties at critical points $(\mathrm{CP})$, as electron density, $\rho\left(r_{\mathrm{CP}}\right)$; Laplacian, $\nabla$ ${ }^{2} \rho\left(r_{\mathrm{CP}}\right)$; electron density curvatures, $\lambda_{1}, \lambda_{2}, \lambda_{3}$; local kinetic $\mathrm{G}\left(r_{\mathrm{CP}}\right)$ and potential $\mathrm{V}\left(r_{\mathrm{CP}}\right)$, energy densities can then be used to describe the molecular structure and to characterize bonding and intermolecular interactions. Topological analysis of experimental electron density was performed analytically using the NEWPROP program. ${ }^{31}$

\subsection{Computational details}

Electronic structure calculations were performed in the framework of density functional theory (DFT) using the local density approximation (LDA) parametrization by Perdew and Zunger ${ }^{32}$, Becke's gradient correction to exchange energy ${ }^{33}$ and Perdew's gradient correction to correlation energy. ${ }^{34}$ Calculations were carried out with the projector-augmented wave (PAW) method ${ }^{35}$ which uses augmented plane waves to describe the full wave functions and densities without shape approximation. The core electrons were described within the frozen core approximation. The plane wave cutoff for wave functions and densities were fixed respectively to 90 and 360 Ry to ensure required precision for topological analysis. Atomic coordinates were obtained from experimental X-ray data obtained after complete multipolar refinement. CA and TTF isolated molecule calculations were conducted using tetragonal supercells $(12.5 \times 12.5 \times 7.5 \AA$ for TTF and $12 \times 12 \times 7 \AA$ for CA) including electrostatic decoupling from periodic images. ${ }^{36}$ For TTF-CA, crystal calculations were performed with three $\mathrm{k}$-points along $\mathbf{a}^{*}{ }^{37}$ Topological analysis of theoretical densities was achieved with the InteGriTy software package using a grid spacing smaller than $0.044 \AA^{38}$

Compared to indirect methods, previous DFT investigation of CT complexes found that charge transfer ( $\left.\mathrm{q}_{\mathrm{CT}}\right)$ is overestimated in the HT phase ${ }^{37,39}$, certainly due to the approximation used for the exchange and correlation potential that suffers from the well-kown problem of the self-interaction error and to a much lesser extent from the missing of the dynamical part of the electron-electron interactions in any local or semi-local approaches. One of the major effects of the too rapid decay of the LDA (or even GGA) exchange-correlation potential is the strong charge delocalization, that leads to a systematic overestimation of $\mathrm{q}_{\mathrm{CT}}$ in the HT phase for instance. ${ }^{40}$ 


\section{Results and discussion}

\subsection{Thermal behaviour of the cell parameters}

The evolution of the cell parameters as a function of temperature gives a clear evidence of the phase transition at $\mathrm{T}_{\mathrm{c}}=81 \mathrm{~K}$ : $\mathbf{a}$ and $\mathbf{c}$ cell parameters display a slope anomaly, while b presents an abrupt jump; in all cases the contraction rate decreases below $\mathrm{T}_{\mathrm{c}}{ }^{41}$ Fig. 1a shows that on cooling $\beta$ decreases from $99.06(2)^{\circ}$ to $98.68(2)^{\circ}$ between 82 and $81 \mathrm{~K}$. However, when warming the increase of the $\beta$ angle occurs between 82 and $83.5 \mathrm{~K}$. This hysteresis of about $1 \mathrm{~K}$ is also observed on the $\mathbf{b}$ parameter (Fig. 1b) and confirms the observed evolution of the intensity of the $\left(\begin{array}{lll}0 & 3 & 0\end{array}\right)$ reflection. ${ }^{41}$ Thus all the cell parameters are sensible to the phase transition, reflecting the 3D character of the temperature induced transition which will be studied using AIM method.

\subsection{Structural properties: Phase transition}

The molecular structures of TTF-CA at 105 and $15 \mathrm{~K}$ with atom labelling are reported in Fig. 2. In the high temperature phase $\left(\mathrm{HT}, \mathrm{T}>\mathrm{T}_{\mathrm{c}}\right.$ ) the TTF-CA space group is $\mathrm{P} \mathrm{2}_{\mathrm{l}} / \mathrm{n}$ (monoclinic), and the TTF and CA molecules form mixed stacks along a axis (Fig. 2a). The TTF and CA molecules lie both on inversion centres respectively at $\left(\begin{array}{l}0 \\ 1 / 2\end{array}\right)$ and $(1 / 21 / 20)$ and all atoms are in general crystallographic positions. Since D and A lie on inversion centres, the asymmetric unit is made of half a TTF molecule and half a CA molecule. Along the stack, the TTF axis, corresponding to the central $\mathrm{C}=\mathrm{C}$ bond, forms an angle of $105.9(5)^{\circ}$ with the $\mathrm{CA} \mathrm{O} \cdots \mathrm{O}$ axis. As mentioned by Mayerle et al. ${ }^{42}$ and in agreement with the general trend observed in TTF-XA $(\mathrm{X}=\mathrm{F}, \mathrm{Cl}, \mathrm{Br}){ }^{42,43}$, the best overlap conditions between the highest occupied molecular orbital (HOMO) of D and the lowest unoccupied molecular orbital (LUMO) of A are fulfilled when the angle between the $\mathrm{O} \cdots \mathrm{O}$ axis of the XA molecule is almost orthogonal to that of the TTF molecule. An edge-on view of the molecules shows several features of interest regarding the molecular configurations and packing. The distance between the TTF and CA molecular centres in the stack is about half the a parameter (i.e. 3.615(2) $\AA$ ). However, the mean planes of the TTF and CA molecules are not parallel. The dihedral angle is $1.6(5)^{\circ}$. This angle induces a close contact along the stack between a sulphur atom S4 and the C15-C17 bond, which has an important contribution to the valence band. ${ }^{37}$ This short contact (i.e. 3.325(2) $\AA$ ) favours the intermolecular interactions needed for the CT.

In the low temperature phase (LT, T< $\mathrm{T}_{\mathrm{c}}$ ), the crystal space group of TTF-CA becomes Pn. While keeping the same lattice translational symmetry, the organic stack gets dimerized. The asymmetric unit is made of one TTF and one CA molecules,

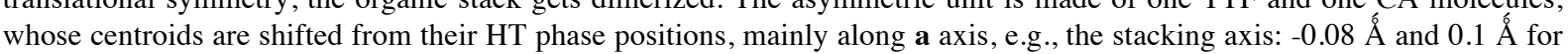
TTF and CA respectively (Fig. 2b). TTF and CA form pairs of D and A characterized by different intra- $\left(\mathrm{d}_{\text {intra }}\right)$ and inter$\left(\mathrm{d}_{\text {inter }}\right)$ pair distances, defined as the distances between the molecular centres $\left(\mathrm{d}_{\text {intra }}=3.416(4) \AA\right.$ and $\left.\mathrm{d}_{\text {inter }}=3.785(4) \AA\right)$. However, as discussed in the dimerization process of tetrathiafulvalene- $p$-bromanil (TTF-BA; $\mathrm{C}_{6} \mathrm{H}_{4} \mathrm{~S}_{4} \quad \mathrm{C}_{6} \mathrm{Br}_{4} \mathrm{O}_{2}$ ) ${ }^{43}$, it is more relevant to compare the closest intermolecular contacts: the shortest atom to atom contact in the stack connects a carbon atom of the central $\mathrm{C}=\mathrm{C}$ bond of TTF to a $\mathrm{CA}$ carbon bonded to an oxygen. Due to the dimerization, two different distances

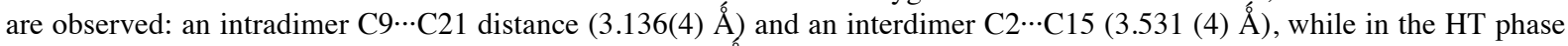
both distances are equivalent by crystal symmetry (3.370 $\AA$ ). Other close contacts originate from the overlap between CA's $\pi$ electrons and the $\mathrm{p}_{\mathrm{z}}$ orbital of one of TTF's sulphur atoms, defining S $\cdots \mathrm{C}-\mathrm{C}$ contacts. Two non equivalent contacts also

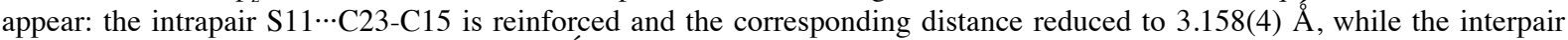

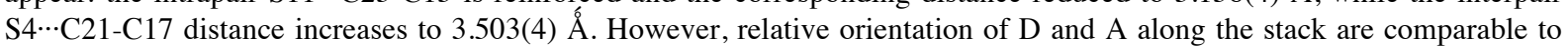
that of the HT phase, the central $\mathrm{C}=\mathrm{C}$ bond of TTF forms an angle of $105.7(1)^{\circ}$ with the $\mathrm{O} \cdots \mathrm{O}$ axes of $\mathrm{CA}$, and the dihedral angle between the mean planes of $\mathrm{D}$ and $\mathrm{A}$ is $1.1(1)^{\circ}$.

Intramolecular geometries of TTF and CA slightly change when cooling below $\mathrm{T}_{\mathrm{c}}$. In this way, the multipolar refinement shows an increase of the TTF $C=C$ bond lengths. This effect is larger for the central $C=C$ bond, from $1.3678(7) \AA$ at $105 \mathrm{~K}$ to $1.3862(7) \AA$ at $15 \mathrm{~K}$. An inverse effect at the limit of the experimental accuracy occurs for the C-S bonds, with distances decreasing from $1.7494(4)$ and $1.7500(4) \AA$ at $105 \mathrm{~K}$ to $1.7429(8), 1.7440(9), 1.7439(9)$ and $1.7499(9) \AA \AA$ at $15 \mathrm{~K}$. This evolution of the $\mathrm{C}=\mathrm{C}$ and $\mathrm{C}-\mathrm{S}$ bonds is related to the change of $\mathrm{q}_{\mathrm{CT}}$ in the complex. The HOMO of TTF is $\pi$-antibonding with respect to the $\mathrm{C}$-S bonds and $\pi$-bonding with respect to the $\mathrm{C}=\mathrm{C}$ bonds, thus, when $\mathrm{q}_{\mathrm{CT}}$ increases, $\mathrm{C}$-S bond lengths decrease, while $\mathrm{C}=\mathrm{C}$ increase. ${ }^{44}$

In the $\mathrm{CA}$ molecule all bond lengths are modified due to the phase transition, i.e. by the increase of $\mathrm{q}_{\mathrm{CT}}$. The single $\mathrm{C}$-C bond lengths decrease, while $\mathrm{C}=\mathrm{C}$ double bonds increase. However the effect is larger for $\mathrm{C}=\mathrm{O}$ and $\mathrm{C}-\mathrm{Cl}$ bond lengths. The $\mathrm{C}=\mathrm{O}$ double bonds increase from $1.2227(4) \AA$ at $105 \mathrm{~K}$ to $1.237(1) \AA$ for both $\mathrm{C}=\mathrm{O}$ bonds at $15 \mathrm{~K}$. The $\mathrm{C}-\mathrm{Cl}$ bond lengths also increase from 1.7062(4) and 1.7037(4) to 1.7234(9), 1.7190(9), 1.7176(9) and 1.7162(9) $\AA$. Hence, as the LUMO of CA is $\pi$ antibonding for both $\mathrm{C}=\mathrm{O}$ and $\mathrm{C}-\mathrm{Cl}$, these bonds increase when $\mathrm{q}_{\mathrm{CT}}$ becomes higher.

Finally, the $\mathrm{U}_{\mathrm{ij}}$ anisotropic thermal parameters at $15 \mathrm{~K}$ are roughly half than those at $105 \mathrm{~K}$. This usual behaviour, also observed in TTF-BA ${ }^{43}$, largely contrasts with the trends observed in other CT complexes, such as DMTTF-CA, where some anisotropic temperature factors along the stacking axis increase below $65 \mathrm{~K}$, suggesting an order-disorder type of phase transition. $^{45}$

We can conclude that the observed geometrical changes of TTF and CA are due to the increase of the $\mathrm{q}_{\mathrm{CT}}$ between D and A in the complex. But, contrary to the neutron LT structure ${ }^{18}$, where the bond lengths in half a TTF molecule are reported to be 
$1-2 \%$ longer than in the other half, this work shows that the NIT does not induce such large differences. In fact, in the LT phase both TTF and CA moieties remain almost centrosymmetric. Our results are in agreement with recent synchrotron results ${ }^{46}$ that show bond lengths differences of the order of the estimated errors $(0.004 \mathrm{~A})$. Therefore, such small differences cannot characterize the phase transition. One reason for the discrepancies between neutron and X-Ray structures arises from the small observation/parameter ratio that allowed only for isotropic estimation of Debye Waller factors in the neutron case whereas a full multipolar refinement was performed on X-ray data.

\subsection{Charge transfer and volumes}

$\mathrm{CT}$ is at the origin of the very interesting electronic, magnetic and optical properties of the CT complexes, and therefore its accurate determination is essential to understand, classify and control them. However, as discussed on the introductory paragraph, it is not a well-defined quantity and there are several experimental and theoretical methods to calculate it. For TTF-CA, it has been estimated from the CT absorption band ${ }^{47}$, from vibrational spectroscopy ${ }^{17,48}$ and by empirical relations between $\mathrm{q}_{\mathrm{CT}}$ and $\mathrm{D}$ or A geometry. ${ }^{49}$ All these methods lead per se to indirect estimations of $\mathrm{q}_{\mathrm{CT}}$. In order to avoid both transferability problems and at the same time to allow for more direct determinations of $\mathrm{q}_{\mathrm{CT}}$, these determinations should be obtained from intrinsic properties, e.g., the electronic structure of the CT complex. These has already been achieved for a couple of NIT compounds on the basis of DFT calculations ${ }^{37,39}$, in particular using "Quantum Theory of Atoms in Molecules". ${ }^{30}$ For TTF-CA, integration over atomic basins leads to $\mathrm{q}_{\mathrm{CT}}$ of 0.48 and 0.64 e respectively at 300 and $40 \mathrm{~K}$. Clearly, $\mathrm{q}_{\mathrm{CT}}$ is overestimated in the HT phase due to the approximation used for the exchange and correlation (see section 2.2).

As discussed above and observed in several TTF-based donor molecules ${ }^{50}$, oxidation of donor molecules produces variations in the central $\mathrm{C}=\mathrm{C}$ and $\mathrm{C}-\mathrm{S}$ bond lengths. First principle studies of $\mathrm{TTF}^{44}$ and $\mathrm{CA}^{51}$ isolated molecules in different oxidation states have established the linear effects of molecular ionicity on bond lengths and several vibrational frequencies. In particular, $\mathrm{C}=\mathrm{O}$ and $\mathrm{C}-\mathrm{Cl}$ bonds of chloranil and central $\mathrm{C}=\mathrm{C}$ and $\mathrm{C}-\mathrm{S}$ bonds in TTF are shown to be particularly sensible to molecular ionicity. These dependences have been related to the contributions of the bonds to the LUMO of CA and HOMO of TTF. However, it has been stressed that these linear relationships may fail due to intermolecular interactions. Moreover, concerning frequency, electron-intramolecular-vibration interactions should not be disregarded. ${ }^{52}$ Examination of the Cambridge Structural Data Base has allowed Umland and co-workers ${ }^{49}$ to establish linear relationships between $\mathrm{q}_{\mathrm{CT}}$ and several functions (ratio and difference) of these $\mathrm{C}=\mathrm{C}$ and $\mathrm{C}-\mathrm{S}$ TTF bonds. This approach was used to estimate $\mathrm{q}_{\mathrm{CT}}$ in TTF-CA ${ }^{18}$ from experimental bond lengths: values of 0.4 and 0.8 e were deduced at 300 and $40 \mathrm{~K}$ respectively.

Starting from our more accurate structural data, the estimates are $\mathrm{q}_{\mathrm{CT}}=0.40 \mathrm{e}$ at $105 \mathrm{~K}$ and $\mathrm{q}_{\mathrm{CT}}=0.65 \mathrm{e}$ at $15 \mathrm{~K}$. However, if we consider the values of the bond lengths of TTF and CA reported for different oxidation states ${ }^{44,51}$, charge transfer variations $\left(\Delta \mathrm{q}_{\mathrm{CT}}\right)$ from $105 \mathrm{~K}$ to $15 \mathrm{~K}$ of 0.4 and 0.5 e are obtained using $\mathrm{C}=\mathrm{O}$ and $\mathrm{C}-\mathrm{Cl}$ bond lengths respectively. From the $\mathrm{TTF} \mathrm{C}=\mathrm{C}$ and C-S bonds, $\Delta \mathrm{q}_{\mathrm{CT}}$ of 0.5 and $0.15 \mathrm{e}$ are obtained respectively. When using bond lengths obtained for crystals of pure TTF or $\mathrm{CA}$ as reference $\left(\mathrm{q}_{\mathrm{CT}}=0\right)$ and the slopes determined by DFT calculations, ${ }^{44,51}$ results become worse. Indeed, $\mathrm{C}-\mathrm{Cl}$ bonds lead to $\mathrm{q}_{\mathrm{CT}} \approx-0.1$ and $\mathrm{q}_{\mathrm{CT}} \approx 0.4 \mathrm{e}, \mathrm{C}-\mathrm{S}$ to $\mathrm{q}_{\mathrm{CT}} \approx 0.8$ and $\mathrm{q}_{\mathrm{CT}} \approx 0.9 \mathrm{e}$ whereas the central $\mathrm{C}=\mathrm{C}$ bond of TTF to $\mathrm{q}_{\mathrm{CT}} \approx 0.7$ and $\mathrm{q}_{\mathrm{CT}} \approx 1.1 \mathrm{e}$, respectively at 105 and $15 \mathrm{~K}$. Thus, using such approaches to determine $\mathrm{q}_{\mathrm{CT}}$ is clearly hazardous, and it gives only qualitative trends for $\Delta \mathrm{q}_{\mathrm{CT}}$. From all these linear relationships $\Delta \mathrm{q}_{\mathrm{CT}}$ ranges from 0.2 to $0.5 \mathrm{e}$ at the NIT. Therefore a direct estimation is needed, based on intrinsic properties, like the electronic structure of the complex. Experimentally, the charge transfer can be obtained from X-ray diffraction data in two ways. First, a refinement in reciprocal space with a modified spherical valence shell $\left(\kappa-\mathrm{P}_{\mathrm{v}}\right.$ formalism $\left.{ }^{6}\right)$, according to equation 4 , allows an estimation of the net atomic charges. A similar method was proposed by Espinosa et al. ${ }^{53}$ to estimate the charge transfer in bis(thiodimethylene)-tetrathiafulvalene tetracyanoquinodimethane (BTDMTTF-TCNQ, $\mathrm{C}_{10} \mathrm{H}_{8} \mathrm{~S}_{6}{ }^{+} \cdot \mathrm{C}_{12} \mathrm{H}_{4} \mathrm{~N}_{4}{ }^{-}$) using a $\mathrm{P}_{1 \mathrm{~m}}$ multipolar refinement, the atomic net charges can be obtained as:

$$
q_{j}=N_{j}-P_{j}^{v a l}
$$

The obtained charge transfer for BTDMTTF-TCNQ $(0.75 \mathrm{e})$ has to be compared with the value derived from the diffuse scattering experiments $(0.5 \mathrm{e}){ }^{54}$

Both $\kappa-P_{v}$ and $P_{\operatorname{lm}}$ refinements have been performed in TTF-CA using electroneutrality constraint, i.e. the total charge of the unit cell is zero. Thus, these two approaches lead respectively to charge transfers of of $0.14 \pm 0.05$ and $0.06 \pm 0.05 \mathrm{e}$ at $105 \mathrm{~K}$, while the values increase to $0.67 \pm 0.03$ and $0.65 \pm 0.03$ e at $15 \mathrm{~K}$. There are not significant differences between the results obtained which show the consistency of the X-ray method.

Finally, the topology of the charge density provides another tool to determine the charge transfer, as the sum of the atomic topological charges obtained by integration of the experimental/theoretical charge density over the atomic basins of all atoms of each molecule leads to the molecular charge and thus to $\mathrm{q}_{\mathrm{CT}}$. These molecular charges and basin volumes obtained are listed in Table 2 and are compared to those obtained for the CA and TTF single crystals. Within TTF-CA at 105K, the experimental charges of CA and TTF are respectively $-0.22(2)$ and $0.20(2)$ e, increasing to $-0.71(2)$ and $+0.77(2)$ e at $15 \mathrm{~K}$. Consequently, the experimental $\mathrm{q}_{\mathrm{CT}}$ is $0.21 \pm 0.02$ at $\mathrm{HT}$ and $0.74 \pm 0.02$ at $\mathrm{LT}$, and $\Delta \mathrm{q}_{\mathrm{CT}}=0.53 \mathrm{e}$. The same approach using the theoretical charge density leads to $\mathrm{q}_{\mathrm{CT}} \approx 0.64 \mathrm{e}$ for the LT phase. How can we gauge our approach? First, our values are in pretty good agreement with the $\kappa-\mathrm{P}_{\mathrm{v}}$ and $\mathrm{P}_{\mathrm{lm}}$ derived charges. Secondly, considering that the unit cell contains two TTF and 
two CA molecules, a comparison between the volume filled by the atomic basins and the unit cell volume allows for gauging the accuracy of the methods. Summation of the atomic volumes (Table 2) reproduces the cell volume within less than $0.3 \%$, for both temperatures at experimental and theoretical levels. This nicely demonstrates the ability of such approaches to tackle such small changes, especially regarding atomic quantities. Correlatively, the net integrated charge of the unit cell is also very close to zero.

As the temperature decreases from $105 \mathrm{~K}$ to $15 \mathrm{~K}$, the TTF volume decreases from $\approx 1.5-2.5 \%$, while the CA's volume remains almost constant. In fact, as CT increases, TTF looses electron density in favour of CA and volume reduction follows. Moreover, from experiments on TTF-based CT complexes ${ }^{55}$ and ab-initio calculations ${ }^{44}$ it is well known that the geometry of TTF is responsive to environmental effects and phase transitions. On the other hand, the CA electron density increases with CT while lattice parameters shrink, thus maintaining constant the CA molecular volume. Additionally, CA peripheral atoms contain a large number of core electrons that prevents large volume variations compared to TTF. This is particularly clear when volumes obtained within a TTF-CA crystal are compared to those obtained on pure TTF and CA single crystals (Table 2).

\subsection{Dipole moment}

The calculation in the crystal axis system of the dipole moment for the dimer in the ionic phase can be performed, considering both contributions: the net atomic charges and the atomic dipoles obtained once the topological analysis has been completed. Obviously, the net charge contribution is mainly along the stacking axis a: $(-12.585,-0.086,0.155) \mathrm{D}$. But the contribution of the atomic dipole moments, $(16.293,-7.027,0.457) \mathrm{D}$, is large, almost lying in the (a,b) plane reflecting not only the $\pi-\pi$ interactions between D and A (along a), but also interstack interactions that are dominated by hydrogen bonds as will be discussed in section 3.6.2.

Following dimerization, a ferroelectric dipole moment $\Delta \mu=\mu_{\text {dimer }}-\mu_{\text {interdimer }}$ appears. Values of $0.36 \mathrm{D}$ in the stack and 0.72 $\mathrm{D}$ in the unit cell are found. The corresponding dipolar energy,

$\mathrm{Wd}=(\Delta \mu)^{2} / 4 \pi \varepsilon_{0} \mathrm{~V},{ }^{56}$ where $\mathrm{V}$ is the volume occupied by the dipole moment, is $6.63 \times 10^{-21} \mathrm{~J}$. This small value compared to $\mathrm{k}_{\mathrm{B}} \mathrm{T}_{\mathrm{N}-\mathrm{I}}\left(\mathrm{Wd} / \mathrm{k}_{\mathrm{B}}=4.8 \mathrm{~K}\right)$ shows that long-range dipolar interactions are not the driving force for the NIT, in agreement with previous findings. ${ }^{18}$

\subsection{Covalent bonds}

A quantitative comparison of the covalent bonds strength can be derived from their topological properties. For each type of covalent bond, similar features are found irrespective of molecular environment, e.g. in TTF-CA, TTF or CA crystals or for calculated isolated molecules. Accumulation of electron density is particularly visible in double bonds, the highest density being observed within the $\mathrm{C}=\mathrm{O}$ bond. The Laplacian of the density also reveals the oxygen lone pairs and the non bonding valence shells of both chlorine and sulphur atoms. Interestingly, while other covalent bonds show almost equal $\lambda_{1}$ and $\lambda_{2}$ curvatures at CPs, indicative of cylindrical symmetry perpendicularly to the bonds, the $\lambda_{1}$ and $\lambda_{2}$ values obtained for all $\mathrm{C}=\mathrm{C}$ bonds differ significantly (about 30\%).

The NIT affects clearly all bond critical points as exemplified by the $\mathrm{C} 2=\mathrm{C} 9$ bond, for which the distance increases from $1.3678(7)$ to $1.3862(7) \AA$, the density decreases from 2.16 to $2.05 \mathrm{e}^{-3}$ and $\nabla^{2} \rho\left(r_{\mathrm{CP}}\right)$ changes from $21 \mathrm{e}^{-5}$ to $18 \mathrm{e} \AA^{-5}$ when decreasing the temperature from 105 to $15 \mathrm{~K}$. Again, this is directly related to the bonding character of the $\mathrm{C}=\mathrm{C}$ bonds in the HOMO of TTF. Both C-S and C-Cl bonds are less responsive to CT variation. For C-S, the average experimental $\nabla^{2} \rho\left(r_{\mathrm{CP}}\right)$ and $\rho\left(r_{\mathrm{CP}}\right)$ vary from $-7.2 \mathrm{e} \AA^{-5}, 1.33 \mathrm{e} \AA^{-3}$ at $105 \mathrm{~K}$ to $-6.2 \mathrm{e}^{-5}, 1.31 \mathrm{e} \AA^{-3}$ at $15 \mathrm{~K}$. These values are in good agreement with the literature. ${ }^{57}$ On average, the $\mathrm{C}-\mathrm{Cl}$ bond $\mathrm{CPs}$ lie at $0.76 \AA$ and $0.96 \AA$ from the $\mathrm{C}$ atom and the $\mathrm{Cl}$ atom respectively. This is directly related to their respective atomic volumes. Moreover, the valence shell charge concentration of the $\mathrm{Cl}$ atom is strongly polarized toward the nearby $\mathrm{C}$ atom (bonded charge concentration). In the direction of such a polar bond, there is a lack of charge accumulation near the more electronegative atom. This behaviour is also characteristic of C-O and C-F bonds. ${ }^{58}$ During the NIT, C-Cl bonds lengths increase from 1.7045(4) to 1.7191(9) $\AA$ in average. $\nabla^{2} \rho\left(r_{\mathrm{CP}}\right)$ and $\rho\left(r_{\mathrm{CP}}\right)$ change from $4.8 \mathrm{e} \AA^{-5}, 1.40 \mathrm{e} \AA^{-3}$ at HT to $-4.1 \mathrm{e} \AA^{-5}, 1.32 \mathrm{e} \AA^{-3}$ at LT.

The overall agreement between theoretical and experimental results is quite good for all bond $\mathrm{CP}$ characteristics. Among the differences, theory gives systematically slightly higher $\rho\left(r_{\mathrm{CP}}\right)$ than that deduced from experiment and lower curvatures along the bond path $\left(\lambda_{3}\right)$ for all bonds except $\mathrm{C}=\mathrm{O}$. The picture becomes more tricky for $\mathrm{C}=\mathrm{O}$ bonds: calculated values of $\nabla^{2} \rho\left(r_{\mathrm{CP}}\right)$ show pronounced deviation from experimental ones, especially for $\lambda_{3}$ : experimental/theoretical values of $\nabla^{2} \rho\left(r_{\mathrm{CP}}\right)$ are $-28 / 3$ $\mathrm{e}^{-5}$ at $105 \mathrm{~K}$ and $-19 /-1$ in average at $15 \mathrm{~K}$. Such a discrepancy between experiment and theory has already been reported in the literature, and explained as originated by the different nature of the radial functions used in DFT and multipolar refinements. ${ }^{59}$ It should also be underlined that, because of the fast variation of the density along the $\mathrm{C}=\mathrm{O}$ bond path, computations of $\lambda_{3}$ and $\nabla^{2} \rho\left(r_{\mathrm{CP}}\right)$ are not straightforward, especially when working with densities on grids. ${ }^{38}$ However, experimental and theoretical $\rho\left(r_{\mathrm{CP}}\right)$ are in excellent agreement: $2.91 / 2.71$ at HT and 2.72/2.63 e $\AA^{-3}$ at LT.

\subsection{Intermolecular Interactions}

Up to now, in the TTF-CA family, crystallographic investigations have characterized the intermolecular interactions only by distances between interacting atoms. Accurate electron density studies may go a step further, using topological analysis to 
describe $\mathrm{H}$ bonds and van der Waals interactions by energetical quantities at the intermolecular CPs associated with the interaction. For example, Espinosa et al. ${ }^{10,60}$ have shown exponential relations between the charge density at $\mathrm{CP}$ and the potential and kinetic energy densities at CP. Such analysis needs very accurate data and a software able to calculate properties at the CP (where the density seldom reaches $0.1 \mathrm{e}^{-3}$ ) with a good precision. Moreover, the corresponding gradient change is very small (flat density) makes the determination of the bond path difficult. This is even more difficult when van der Waals interactions are concerned. The experimental studies described here are accurate enough to characterize the topological properties at $\mathrm{CP}$ within a relative error estimated to a maximum of $20 \%$. The most difficult problem is to locate accurately the $\mathrm{CP}$. When the density is obtained from analytical model like multipole refinement, an analytical calculation of the derivatives of $\rho(\vec{r})$ for estimating the topological properties may be performed; ${ }^{31}$ in that way the errors are limited only to the experimental error on the charge density. The topological analysis of the DFT density has been done on a grid ${ }^{38}$ the positions and the properties of the CPS depend on the grid size and to low extended on the interpolation procedure when the charge density is flat.

\subsubsection{Intrastack Interactions}

Starting from the published structures at 300 and $40 \mathrm{~K}{ }^{18}$, Oison et al. ${ }^{37}$ have conducted a thorough ab-initio study of TTFCA. Despite differences in molecular geometries discussed in sect. 3.2, our experimental and theoretical findings on intermolecular interactions are consistent with their results. In particular, topological analysis of the charge density of the HT phase shows the existence of $(3,-1)$ CPs lying between TTF and CA in a plane parallel to the molecules. According to their Laplacian, charge density and potential energy density, only the most important contacts are reported in Table 3 and discussed here. The strongest contact between D and A molecules is clearly visible in Fig. 3a. At HT, a 0.06 e $^{-3}$ isocontour links the two molecules via the $\mathrm{S} 4 \cdots \mathrm{C} 15-\mathrm{C} 17$ contact. This is directly related to the HOMO-LUMO overlap that shows up in the valence band. ${ }^{37}$ The positive Laplacian $\left(0.59 / 0.56 \mathrm{e}^{-5}\right)$ and the charge density $\left(0.06 / 0.06 \mathrm{e} \AA^{-3}\right)$ at the CP are characteristic of a closed-shell interaction (Fig. 2a). The agreement between experimental and theoretical results is quite good, but discrepancies are observed in the $\mathrm{CP}$ locations and ellipticities as discussed previously. Experimentally, the $\mathrm{CP}$ is closer to the $\mathrm{C} 17$ atom than to $\mathrm{C} 15$, whereas theoretically $\mathrm{C} 15$ and $\mathrm{C} 17$ distances to the $\mathrm{CP}$ are similar. Both experimental and theoretical ellipticities are quite large. This is an indication that the difference in CP location arises from the flatness of the charge density distribution. In the same way, the central $\mathrm{C}=\mathrm{C}$ bond of TTF is connected to $\mathrm{C} 15$ in the experimental density and to $\mathrm{C} 17$ in the theoretical one, again with quite large ellipticities. Moreover, both contacts involve the same carbon atoms of CA, namely $\mathrm{C} 17$ and $\mathrm{C} 15$. Consequently, it becomes very risky to deduce whether these contacts link individual atoms or bridge over bonds. Increased theoretical and experimental precision is required to come to a conclusion for such low and flat charge density regions.

Other $(3,-1)$ CPs are found between the S5 atom and both chlorine atoms of the asymmetric unit. These C119 $\cdots \mathrm{S} 5$ and $\mathrm{C} 120 \cdots \mathrm{S} 5$ contacts exhibit similar characteristics with experimental positive Laplacian of about $0.43 \mathrm{e} \AA^{-5}$, a small charge density of $0.04-0.05 \mathrm{e}^{-3}$, and a potential energy density of about $-8.1 \mathrm{~kJ} / \mathrm{mol}$. CPs in $\mathrm{Cl} \cdots \mathrm{S}$ contacts are not very frequent in literature. Compared to $\mathrm{S} \cdots \mathrm{S}$ contacts reported in L-cystine ${ }^{57 a}$, Laplacian, charge density and potential energy density are stronger.

In the LT phase, the creation of pairs of DA dimers clearly shows up (Fig. 3b) with an increase of intradimer charge density. Due to the dimerization process, different inter- and intra dimer $\mathrm{CP}$ are observed (Fig. 2b, Table 3). The S $\cdots \mathrm{C}-\mathrm{C}$ intra dimer contact remains the dominant one, with a $81 \%$ increase in its strength as measured by $\mathrm{V}(\mathrm{r})$. In the dimer pair the strength of the $\mathrm{C} \cdots \mathrm{C}-\mathrm{C}$ and $\mathrm{S} 5 \cdots \mathrm{Cl} 20$ increases, while that of S5 $\cdots \mathrm{Cl} 19$ is slightly reduced. All inter-dimer contacts are systematically reduced and the observed reduction of $\mathrm{CP}$ characteristics, such as potential energy density, demonstrates their ability to investigate that tiny structural changes. The overall agreement between experimental and theoretical results is quite good.

\subsubsection{Interchain Interactions}

As $\mathbf{c}$ cell parameter is twice the length of the two other ones, the stacks are too far along $\mathbf{c}$ to allow any atom to atom interactions. Consequently, contacts occur between stacks related by translation along $\mathbf{b}$ axis, and by the $\mathrm{n}$ glide plane symmetry which remains in the ionic phase $\left(\mathrm{P} 2_{1} / \mathrm{n}\right.$ to $\left.\mathrm{Pn}\right)$. Interestingly, $(3,-1) \mathrm{CPs}$ are found not only on $\mathrm{C}-\mathrm{H} \cdots \mathrm{O}, \mathrm{Cl} \cdots \mathrm{H}$ and $\mathrm{Cl} \cdots \mathrm{S}$ contacts between $\mathrm{D}$ and $\mathrm{A}$ molecules, but also for $\mathrm{S} \cdots \mathrm{H}(\mathrm{D}-\mathrm{D})$ and $\mathrm{Cl} \cdots \mathrm{Cl}(\mathrm{A}-\mathrm{A})$ ones, as shown in Fig. 4a and in Fig. $4 \mathrm{~b}$; the topological characteristics of the strongest interstack interactions for both HT and LT phases are given in Table 4.

At first observed by the temperature-dependence of the thermal expansion tensor ${ }^{61}$, and as discussed by structure analysis ${ }^{18}$ and DFT calculations ${ }^{37,62}$, interchain hydrogen bonds are the dominant interaction in TTF-CA for both inter and intra stack interactions. In both HT and LT phases each CA oxygen atom is linked to two TTF molecules through two different hydrogen bonds. First, as shown in Figures $4 \mathrm{a}$ and $4 \mathrm{~b}$, the oxygen atoms accept the strongest bond interaction: O18 $\cdots \mathrm{H} 6-\mathrm{C} 1$ and $\mathrm{O} 24 \cdots \mathrm{H} 13-\mathrm{C} 8$ its symmetry equivalent in the HT phase, are almost linear in the $[1,2,0]$ direction and are reinforced in the LT phase, but asymmetrically, O18 $\cdots \mathrm{H} 6$ being the strongest. In the other lone pair direction the $\mathrm{O} 18 \cdots \mathrm{H} 14-\mathrm{C} 10$ and $\mathrm{O} 24 \cdots \mathrm{H} 7-\mathrm{C} 3$ interactions are bent and therefore weaker. They are also strengthened in the ionic phase as their potential energy density increases by more than $40 \%$. This is related to the contraction of the crystal which is the largest in the plane containing this $\mathrm{C}-\mathrm{H} \cdots \mathrm{O}$ network. ${ }^{61}$

The fact that the $\mathrm{H}$ bonds are the dominant contacts of all the intra- and interstack interactions contrasts with the first idea of the quasi-one-dimensionality of TTF-CA. The CT was for a long time considered to happen as a chain along a axis, with weak or no interchain coupling. In this way, the electrostatic interaction between the stacks was assumed to be much smaller 
than the intrastack one. However, as discussed above, the temperature evolution of the cell parameters does not agree with this assumption. Furthermore, as reported by Kawamoto and co-workers ${ }^{63}$, if the charge distribution on atoms is considered, the electrostatic energy between TTF and CA aligned along the $[1,2,0]$ direction is attractive and superior to the repulsive one between CA molecules in the $\mathbf{b}$ direction; It is in clear agreement with the above analysis of the dipole moment. On the other hand, it is well established that valence and conduction bands have a clear one-dimensional character. ${ }^{37}$ Thus, the dimensionality of TTF-CA depends strongly on the property of interest.

In TTF-BA, the estimation of $\mathrm{q}_{\mathrm{CT}}$ by the Umland empirical method ${ }^{49}$ seems to show that dimerization does not imply CT variation because this complex is already ionic at room temperature. ${ }^{43}$ Can we find a rational explanation by looking at the molecular packing and the corresponding intermolecular interactions? In TTF-BA, (space group P-1 to P1), the D and A molecules alternate along $\mathbf{a}$ and $\mathbf{b}$ crystallographic axes, the longest axes of the $\mathrm{D}$ and A molecules of the two different stacks being quasiparallel. This geometry leads to bent $\mathrm{H}$ bonds, with distances similar to those observed in TTF-CA and therefore of equivalent strength. The main difference between the two CT complexes comes from the halogen-halogen $(\mathrm{C} 1-\mathrm{X} 1 \cdots \mathrm{X} 2-$ C2) interactions. Depending on the geometric parameters two types of halogen-halogen interactions have been defined. ${ }^{64,65} \mathrm{In}$ the first one, called head-on contact, both $\mathrm{C}-\mathrm{X}$ bonds form a nearly collinear arrangement, with contacts angles $\theta_{1}$ (C1$\mathrm{X} 1 \cdots \mathrm{X} 2)$ and $\theta_{2}(\mathrm{X} 1 \cdots \mathrm{X} 2-\mathrm{C} 2)$ around $160 \pm 10^{\circ}$. These contacts may arise when a particular crystallographic operation relates the two halogen atoms; the interaction is repulsive as evidenced by the electrostatic potential. ${ }^{66}$ In the second type, the interaction is attractive and is called side-on or polarization-induced contact, one of the angles is $170 \pm 10^{\circ}$ and the other $90 \pm 10^{\circ}{ }^{64,65}$ The preference to form one of these two types of halogen-halogen contacts is related to the polarizability of the halogen atoms. In TTF-BA attractive type II interactions occur along the [llll 11 and $[1,1,-1]$ directions with $\mathrm{Br} \cdots \mathrm{Br}$ distances of $3.566(3)$ at $100 \mathrm{~K}$ and $3.540(3) \AA$ at $15 \mathrm{~K}$, much smaller than the sum of van der Waals radii (3.70 $\AA$ ). In TTF$\mathrm{CA}, \mathrm{Cl} \cdots \mathrm{Cl}$ interactions are repulsive type I interactions with distances of about 3.470(3) $\AA$ close to the sum of van der Waals radii $(3.50 \AA)$.

In conclusion, attractive interactions lead to $\mathrm{X} \cdots \mathrm{X}$ distances smaller than van der Waals contacts, whereas the repulsive $\mathrm{Cl} \ldots \mathrm{Cl}$ interactions do not allow such shortening. Topological parameters of the $\mathrm{Cl} \cdots \mathrm{Cl}$ contacts do not change very much upon the phase transition, as shown in Table 4.

\section{Conclusion and perspectives}

Accurate X-ray measurement and electron density modelling is a necessary tool to directly investigate intermolecular interactions and tiny charge transfers. For the TTF-CA crystal, the topological analysis of the intermolecular interactions using theoretical DFT and experimental electron densities show that $\mathrm{C}-\mathrm{H} \cdots \mathrm{O}$ interstack contacts are the strongest interactions and are reinforced in the LT phase, whereas the strength of the $\mathrm{Cl} \cdots \mathrm{Cl}$ interactions, which may be repulsive in that case, do not change when crossing the transition. The role of the latter is still not clear and needs further discussion as for example electrostatic potential calculations.

This study also demonstrates that agreement between theory and experiment is not fully satisfactory and requires more accurate calculations and modelling: theory is not able to reproduce the charge transfer occurring during the NIT and both experiment and theory disagree in the position of the critical points of some important intermolecular interactions as $\mathrm{Cl} \cdots \mathrm{Cl}$ for example. More critical is the disagreement for finding the $\mathrm{C} 2=\mathrm{C} 2 \cdots \mathrm{C} 15$ (or $\mathrm{C} 17$ ) interaction pathway: both methods find a $(3,-1) \mathrm{CP}$ with similar characteristics but experiment would prefer a $\mathrm{C} 2 \cdots \mathrm{C} 15$ interaction when theory finds a $\mathrm{C} 2 \cdots \mathrm{C} 17$ interaction. Therefore the present accuracy does not allow to discriminate if this interaction links individual atoms (and which atoms) or bridges over bonds.

By comparison with previous work ${ }^{43}$, halogen... halogen interactions need a better description in order to know when and why these interactions are attractive or repulsive and at which level they compete with $\mathrm{C}-\mathrm{H} \cdots \mathrm{O}$ interactions during the phase transition process. In order to rank these interactions charge density and related electrostatic potential of TTF $-\mathrm{XA}(\mathrm{X}=\mathrm{F}$, $\mathrm{Br}, \mathrm{I})$ are underway using high resolution X-ray diffraction: as an example Fig. 5 shows the contribution of the $\mathrm{Cl}$ atom to the electrostatic potential of CA in the ionic phase; clearly two negative lobes appear which should be related with the attractive or repulsive behaviour of $\mathrm{X} \cdots \mathrm{X}$ interactions. Although the potential distribution is the same than that observed in the vicinity of the terminal halide ligand of $\mathrm{CH}_{3} \mathrm{Cl}^{66}$, where the electrostatic energy of the minima is $-80 \mathrm{~kJ} / \mathrm{mol}$; in TTF-CA - 25 and $148 \mathrm{~kJ} / \mathrm{mol}$ are respectively obtained at 105 and $15 \mathrm{~K}$ Therefore, together with the TTF, CA and TTF-CA charge densities, we will have a large panorama of the interactions as a function of the charges, multipole moments, polarizabilities of the halogen atoms and of the geometry and environment of the contacts.

It has been shown that the charge transfer is not an unambiguously defined quantity that can be directly (charge density modelling) or indirectly estimated from molecular geometry or IR spectra. Although D and A molecular geometries are sensible to the charge transfer, its estimation by empirical models is only qualitative: examination of different bond lengths leads to different $\mathrm{q}_{\mathrm{CT}}$ values. Similarly, the variation of $\mathrm{q}_{\mathrm{CT}}$ is supposed to be proportional to the frequency of typical phonon modes (e.g., $\mathrm{C}=\mathrm{O}$ stretching modes of $\mathrm{CA}$ ). Moreover, these methods present inevitable ambiguities: molecular geometries and frequencies of single TTF and CA molecules are used as references, because those of TTF-CA with $\mathrm{q}_{\mathrm{CT}}=0$ and $\mathrm{q}_{\mathrm{CT}}=1 \mathrm{e}$ are not known.

To our opinion the best way to determine the charges remains in the analysis of the experimental or theoretical charge density. The case of TTF-CA complex has been chosen because the CT is less than one electron shared by 26 atoms. We have shown that both $\kappa-\mathrm{P}_{\mathrm{v}}$ and $\mathrm{P}_{\operatorname{lm}}$ models give similar and realistic results for the charge transfer. However, they can not be compared with theoretical results, except if we transform the charge density into the theoretical structure factors. A direct 
comparison is possible with a topological analysis of the charge density as described by Bader that allows for a direct accurate estimation of the charge transfer occurring during the NIT (in the experimental case,$\Delta \mathrm{q}_{\mathrm{CT}}=0.53 \mathrm{e}$ ).

In conclusion these results show that Kappa, multipole and topological methods applied to X-ray data lead to statistically similar results respectively, $\Delta \mathrm{q}_{\mathrm{C}}=0.53,0.59$ and $0.53 \mathrm{e}$. This raises the following question; why do we obtain such a good agreement as the definitions of the $\kappa-\mathrm{P}_{\mathrm{v}}$ and topological charges are clearly different: $\kappa-\mathrm{P}_{\mathrm{v}}$ (or multipolar) charges are integrated from reciprocal space calculations on spherical volumes obtained from expanded or contracted HF free infinite atoms whereas the topological charges are integrated inside very non spherical atomic basins of limited volumes. It evidently leads to very different atomic net charges as shown in Table 5 which compares them in the LT phase.

An explanation may be the following: in TTF CA the charge which we consider is summed up over the whole TTF or CA molecule and the different shapes of atoms therefore has no real importance because the charge is integrated over the whole molecular volume. Therefore, as there is an electroneutrality constraint in the refinement process and as we have shown that the total charge summed over all atomic basins of the unit cell is only -0.02 and $0.06 \mathrm{e}$ at $105 \mathrm{~K}$ and $15 \mathrm{~K}$, instead of zero (Table 3), the small differences between the values obtained from the two methods comes only from the periphery of the molecules which electron density is small. Therefore as both charge partitioning agree it strengthens the X-ray approach but this conclusion drawn in this particular case needs to be discussed and confirmed by other charge estimations on other selected charge transfer materials or ionic species.

\section{Acknowledgements}

Calculations have been supported by the "Centre Informatique National de l'Enseignement Supérieur" (CINES-France). CK is greatful to P. E. Blöchl for his PAW code and to N. Audiffren and Ph. Falandry (CINES-France) respectively for parallelization and graphical interfacing (OpenDX) of InteGriTy. PG, SD and CL are especially indebted to A. Bouché and E. Wenger (Service Commun de Diffraction X, UHP Nancy 1) and to Drs J. Angyán and Iann Gerber for useful discussions. PG is grateful to the Ministère de l'Education National et de la Recherche for a doctoral fellowship.

\section{References}

1 P. Coppens, X-Ray Charge Densities and Chemical Bonding, 1997, Oxford University Press UK

2 V. G. Tsirelson and R. P. Ozerov Electron Density and Bonding in Crystals, 1996, Inst. Of Physics Publishing Philadelphia USA.

3 F.L. Hirshfeld, Theor. Chem. Acta, 1977, 44, 129.

4 P. Coppens, Phys. Rev. Lett., 1975, 35, 98.

5 R. S. Mulliken, J. Chem. Phys., 1955, 23, 1833.

6 P. Coppens, T. N. Guru Row, P. Leung, E. D. Stevens, P. J. Becker and Y. W. Yang, Acta Cryst., 1979, A35, 63

7 N. Bouhmaida, N. E. Ghermani, C. Lecomte and A. Thalal, Acta Cryst., 1999, A55, 729.

8 (a). G. Ángyán and C. Chipot, Int. J. Quantum Chem.,1994, 52, 17; (b) J. G. Ángyán, C. Chipot, F. Dehez, C. Hättig, G. Jansen and C. Millot, J. Comp. Chem., 2003, 24, 997.

9 R. F. W. Bader, J. Chem. Phys., 1980, 73, 2871.

10 Espinosa, J. Molins and C. Lecomte Chem. Phys. Lett., 1998, 285, 170.

11 J. B. Torrance, A. Girlando, J. J. Mayerle, J. I. Crowley, V. Y. Lee, P. Batail and S. J. Laplaca, Phys. Rev. Lett., $1981,47,1747$.

12 Y. Tokura, T. Koda, T. Mitani and G. Saito, Solid State Communications, 1982, 43, 757.

13 J. B. Torrance, J. E. Vazquez, J. J. Mayerle and V. Y. Lee, Phys. Rev. Lett., 1981, 46, 253.

14 A. Girlando and A. Painelli, Phys. Rev., 1986, B34, 2131.

15 S. Koshihara, Y. Takahashi, H. Sakai, Y. Tokura and T. Luty, J. Phys. Chem., 1999, B103, 2592.

16 E. Collet, M. H. Lemée-Cailleau, M. Buron-LeCointe, H. Cailleau, M. Wulff, S. Koshihara, M. Meyer, L. Toupet, P. Rabiller and S. Techert, Science, 2003, 300, 612 .

17 A.Girlando, R. Bozio, C. Pecile and J. B. Torrance, Phys. Rev., 1982, B26, 2306.

18 M. L. LeCointe, M. H. Lemée-Cailleau, H. Cailleau, B. Toudic, L. Toupet, G. Heger, F. Moussa, P. Scheiss, K. H. Kraft and N. Karl, Phys. Rev., 1995, B51, 3374.

19 R. Argoud, P. Fertey, P. Bordet and J. Reymann, Acta Cryst., 2000, A56, s221.

20 J. Cosier and A. M. Glazer, J. Appl. Cryst. , 1986, 19, 105.

21 Z. Otwinowski, W. Minor, DENZO-SMN, Methods in Enzymology, Vol. 276, Macromolecular Crystal-lography, Part A, edited by C. W.

22 CrysAlis, Oxford Diffraction Poland Sp., CCD Data Reduction GUI, version 1.171.27p5 beta

23 Blessing, R. H. Crystallogr. Rev. 1987, 1, 3. (New version 1998).

24 M. Souhassou, E. Espinosa, C. Lecomte, R. H. Blessing, Acta Cryst., 1995, B51, 661.

25 G. M. Sheldrick, SHELXL97. Programs for Crystal Structure Analysis (Release 97-2), University of Göttingen, Germany (1997).

26 N. Hansen and P. Coppens, Acta Cryst., 1978, A34, 909.

27 C. Jelsch, V. Pichon-Pesme, B. Bartosz, B. Guillot and C. Lecomte, to be published.

28 D. W. J. Cruikshank, Acta Cryst., 1949, 2, 65.

29 B. Rees, Acta Cryst.,1976, A32, 483.

30 R. Bader, Atoms in Molecules: A Quantum Theory (Oxford University Press: New York, 1994).

31 M. Souhassou, R. H. Blessing, J. Appl. Cryst., 1999, 32, 210.

32 J. P. Perdew and A. Zunger, Phys. Rev., 1981, B23, 5048.

33 A. D. Becke, J. Chem. Phys. 1992, 96, 2155.

34 J. P. Perdew, Phys. Rev. B, 1986, 33, 8822.

35 P. E. Blöchl, Phys. Rev. B, 1994, 50, 17953

36 P. E. Blöchl, J. Chem. Phys., 1995, 103, 7422.

37 V. Oison, C. Katan, P. Rabiller, M. Souhassou, C. Koening, Phys. Rev. B, 2003, 67, 035120.

38 C. Katan, P. Rabiller, C. Lecomte, M. Guezo, V. Oison, and M. Souhassou, J. Appl. Cryst. 2003, 36, 65. 
39 V. Oison, P. Rabiller, C. Katan, J. Phys. Chem.., 2004, A108, 11049.

40 (a) R. Merkle, A. Savin and H. Preuss, J. Chem. Phys., 1992, 97, 9216; (b) E. Ruiz, D. R. Salahub and A. Vela, J. Phys. Chem., 1996, 100, 12265; (c) Y. K. Zhang and W. T. Yang, J. Chem. Phys., 1998, 109, 2604.

41 M. Buron-Le Cointe, M. H. Lemee-Cailleau, H. Cailleau, B. Toudic, A. Moreac, F. Moussa, C. Ayache and N. Karl, Phys. Rev., 2003, B68, 064103.

42 J. J. Mayerle, J. B. Torrance and J. I. Crowley, Acta. Cryst., 1979, B35, 2988.

43 P. Garcia, S. Dahaoui, P. Fertey, E. Wenger and C. Lecomte, Phys. Rev., 2005, B72, 104115.

44 C. Katan; J. Phys. Chem., 1999, A103, 1407.

45 Y. Nogami, M. Taoda, K. Oshima, S. Aoki, T. Nakayama and A. Miura, Synth. Met., 1995, 70, 1219.

46 A. Tomita and S. Koshihara, 2006, in " First France-Japan Advanced School on Chemistry and Physics of Molecular Materials".

47 C. S. Jacobsen and J. B. Torrance, J. Chem. Phys., 1983, 78, 112.

48 A. Girlando, I. Zanon, R. Bozio and C. Pecile, J. Chem. Phys., 1978, 68, 22.

49 T. C. Umland, S. Allie, T. Kuhlmann and P. Coppens, J. Phys. Chem., 1988, 92, 6456.

50 P. Guionneau, C. J. Kepert, G. Bravic, D. Chasseau, M. R. Truter, M. Kurmoo and P. Day, Synth. Meta., $1997,86,1973$.

51 C. Katan, P. E. Blochl, P. Margl and C. Koeniq, Phys. Rev., 1996, B53, 12112.

52 C. Pecile, A. Painelli and A. Girlando, Mol. Cryst. Liq. Cryst., 1989, 171, 69.

53 E. Espinosa, E. Molins and C. Lecomte, Phys. Rev. B, 1997, 56, 1820.

54 C. Rovira, J. Tarrés, J. Llorca, E. Molins, J. Veciana, S. Yang, D. O. Cowan, C. Garrigou-Lagrange, J. Amiell, P. Delhaes, E. Canadell and J. P. Pouget, Phys. Rev. , 1995, B52, 8747.

55 (a) J. L. Segura and N. Martin, Angew. Chem. Int. Ed., 2001, 40, 1372.; (b) M. R. Bryce, Adv. Mater., $1999,1,11$.

56 J. Lajzerowicz and J. Legrand, Phys. Rev. , 1978, B17, 1438.

57 (a) S. Dahaoui, V. Pichon-Pesme, J. A. K. Howard and C. Lecomte, J. Phys. Chem. A., 1999, 103, 6240; (b) S. Pillet, M. Souhassou, Y. Pontillon, A. Caneschi, D. Gatteschi and C. Lecomte, New J. Chem., 2001, 1, 131; (c) F. Benabicha, V. Pichon-Pesme, C. Jelsch, C. Lecomte and A. Khmou, Acta. Cryst., 2000, B56, 155; R. Guillot, N. Muzet, S. Dahaoui, C. Lecomte and C. Jelsch, Acta. Cryst., 2001, B57, 567.

58 A. Bachn D. Lentz and P. Luger, J. Phys. Chem. , 2001, A105, 7405.

59 A. Volkov, and P. Coppens, Acta. Cryst., 2001, A57, 395.

60 E. Espinosa, M. Souhassou, H. Lachekar and C. Lecomte, Acta. Cryst. , 1999, B55, 563.

61 P. Batail, S. J. LaPlaca, J. J. Mayerle and J. B. Torrance, J. Am. Chem. Soc., 1981, 103, 951.

62 V. Oison, C. Katan and C. Koening, J. Phys. Chem., 2001, A105, 4300.

63 T. Kawamoto, T. Iizuka-Sakano, Y. Shimoi and S. Abe, Phys. Rev., 2001, B64, 205107.

64 T. Sakurai, M. Sundaralingam, and G. A. Jeffrey, Acta Cryst., 1963, 16, 354.

65 N. Ramasubbu, R. Parthasarathy and P. Murray-Rust, J. Am. Chem. Soc., 1986, 108, 4308.

66 L. Brammer, E. A. Bruton, and P. Sherwood, Cryst. Growth Des., 2001, 1, 277.

Table 1 Experimental details

\begin{tabular}{|c|c|c|c|c|}
\hline & TTF & $\mathrm{CA}$ & TTF-CA & TTF-CA \\
\hline Formula & $\mathrm{C}_{6} \mathrm{~S}_{4} \mathrm{H}_{4}$ & $\mathrm{C}_{6} \mathrm{Cl}_{4} \mathrm{O}_{2}$ & $\mathrm{C}_{12} \mathrm{~S}_{4} \mathrm{Cl}_{4} \mathrm{O}_{2} \mathrm{H}_{4}$ & $\mathrm{C}_{12} \mathrm{~S}_{4} \mathrm{Cl}_{4} \mathrm{O}_{2} \mathrm{H}_{4}$ \\
\hline $\mathrm{M}$ & 817.33 & 491.72 & 900.38 & 900.38 \\
\hline $\mathrm{T}(\mathrm{K})$ & 100 & 100 & 105 & 15 \\
\hline Crystal system & Triclinic & Monoclinic & Monoclinic & Monoclinic \\
\hline Space group & $\mathrm{P}-1$ & $\mathrm{P} 2_{1} / \mathrm{c}$ & $\mathrm{P} 2_{1} / \mathrm{n}$ & $\mathrm{Pn}$ \\
\hline $\begin{array}{l}\text { Unit cell } \\
\text { dimensions }\end{array}$ & $\begin{array}{l}\mathrm{a}=8.3101(3) \AA \\
\mathrm{b}=12.7800(3) \AA \\
\mathrm{c}=7.9582(1) \AA \\
\alpha=99.627(3)^{\circ} \\
\beta=95.906(3)^{\circ} \\
\gamma=101.083(3)^{\circ}\end{array}$ & $\begin{array}{l}a=8.574(1) \AA \dot{~} \\
b=5.690(1) \AA \dot{~} \\
c=8.700(1) \AA \\
\beta=105.937(8)^{\circ}\end{array}$ & $\begin{array}{l}\mathrm{a}=7.2297(5) \AA \\
\mathrm{b}=7.5933(3) \AA \delta \\
\mathrm{c}=14.4980(9) \AA \\
\beta=99.15(3)^{\circ}\end{array}$ & $\begin{array}{l}\mathrm{a}=7.1999(9) \AA \AA \\
\mathrm{b}=7.5556(6) \AA \\
\mathrm{c}=14.479(1) \AA \\
\beta=98.511(8)^{\circ}\end{array}$ \\
\hline Volume $\left(\AA^{3}\right)$ & 817.33 & 403.43 & $786.2(2)$ & $779.02(13)$ \\
\hline $\mathrm{Z}$ & 4 & 2 & 2 & 2 \\
\hline $\begin{array}{l}\text { Reflections } \\
\text { collected/ } \\
\text { independent }\end{array}$ & $141108 / 16513$ & $85699 / 5445$ & $168470 / 9237$ & $75177 / 14634$ \\
\hline $\begin{array}{l}\mu(\mathrm{Mo}-\mathrm{K} \alpha)\left(\mathrm{mm}^{-1}\right), \\
\text { Resolution }\left(\AA^{-1}\right)\end{array}$ & $1.09,1.10$ & $1.41,1.19$ & $1.28,1.14$ & $1.29,1.16$ \\
\hline $\mathrm{R}_{\text {int }}$ & 0.0741 & 0.0269 & 0.0364 & 0.0266 \\
\hline $\mathrm{R}(\mathrm{I}>3 \sigma(\mathrm{I}))^{a}$ & 0.0142 & 0.0167 & 0.0141 & 0.0138 \\
\hline
\end{tabular}

Table 2 Topological molecular volumes $\left(\AA^{3}\right)$ and charges (e), compared to those obtained with $\kappa-\mathrm{P}_{\mathrm{v}}$ and multipolar refinement. For TTF* and $\mathrm{CA}^{*}$, data are obtained from experiments on pure TTF and CA single crystals. Other results are relative to molecules in single crystals of TTF-CA at either 105 or $15 \mathrm{~K}$.

\begin{tabular}{|l|c|c|c|c|c|c|}
\hline & $\mathrm{TTF}^{*}$ & $\mathrm{TTF}^{105 \mathrm{~K}}$ & $\mathrm{TTF}^{15 \mathrm{~K}}$ & $\mathrm{CA}^{*}$ & $\mathrm{CA}^{105 \mathrm{~K}}$ & $\mathrm{CA}^{15 \mathrm{~K}}$ \\
\hline $\mathrm{V}_{\exp }$ & 205.12 & 191.24 & 186.49 & 204.92 & 201.52 & 201.69 \\
\hline $\mathrm{V}_{\text {theo }}$ & & 189.92 & 187.07 & & 202.82 & 202.27 \\
\hline $\mathrm{q}_{\text {exp }}$ & 0.01 & 0.20 & 0.77 & -0.02 & -0.22 & -0.71 \\
\hline $\mathrm{q}_{\text {theo }}$ & 0.54 & 0.63 & & -0.50 & -0.64 \\
\hline \begin{tabular}{l}
$\mathrm{q}_{\text {exp, к-Pv }}^{\text {refinement }}$ \\
\hline $\begin{array}{l}\mathrm{q} \text { exp, mult } \\
\text { refinement }\end{array}$
\end{tabular} & 0.14 & 0.67 & & -0.14 & -0.67 \\
\hline
\end{tabular}


Table 3 Topological characteristics of the electron density at selected $(3,-1)$ intrachain CPs. The $\lambda_{1}, \lambda_{2}, \lambda_{3}\left(\mathrm{e} \AA^{-5}\right)$ are the curvatures of the three principal axes of the Hessian matrix, $\nabla^{2} \rho\left(\mathrm{e} \AA^{-5}\right)$ is the Laplacian of the electron density, $\rho\left(\mathrm{e} \AA^{-3}\right)$ is the electron density $\varepsilon$ is the ellipticity value and $\mathrm{V}(\mathrm{r}) \quad(\mathrm{kJ} / \mathrm{mol})$ is the potential energy density. The values $\mathrm{d}_{1}, \mathrm{~d}_{2}$ and $\mathrm{d}_{3}(\AA)$ represent the distances from the CP to the attractors 1, 2 and 3. First line: experimental electron density, second line: theoretical electron density.

\begin{tabular}{|c|c|c|c|c|c|c|c|c|c|c|}
\hline 105K & $\mathrm{d} 1$ & $\mathrm{~d} 2$ & d3 & $\nabla^{2} \rho$ & $\rho$ & $\varepsilon$ & $V(r)$ & $\lambda_{3}$ & $\lambda_{2}$ & $\overline{\lambda_{1}}$ \\
\hline $\mathrm{S} 4 \cdots \mathrm{C} 17-\mathrm{C} 15$ & $\begin{array}{l}1.816 \\
1.818 \\
\end{array}$ & $\begin{array}{l}1.628 \\
1.692\end{array}$ & $\begin{array}{l}1.802 \\
1.688 \\
\end{array}$ & $\begin{array}{l}0.59 \\
0.56 \\
\end{array}$ & $\begin{array}{l}0.06 \\
0.06\end{array}$ & $\begin{array}{l}1.53 \\
5.66\end{array}$ & $\begin{array}{l}-11.1 \\
-11.0\end{array}$ & $\begin{array}{l}0.77 \\
0.72\end{array}$ & $\begin{array}{r}-0.05 \\
-0.02 \\
\end{array}$ & $\begin{array}{l}-0.13 \\
-0.14 \\
\end{array}$ \\
\hline $\mathrm{C} 15 \cdots \mathrm{C} 2-\mathrm{C} 2 \mathrm{~A}^{a}$ & 1.633 & 1.742 & 2.194 & 0.45 & 0.04 & 6.68 & -7.0 & 0.51 & -0.01 & -0.05 \\
\hline $\mathrm{C} 17 \cdots \mathrm{C} 2-\mathrm{C} 2 \mathrm{~A}^{b}$ & 1.713 & 1.809 & 1.856 & 0.43 & 0.04 & 7.52 & -6.8 & 0.51 & -0.008 & -0.01 \\
\hline $\mathrm{C} 119 \cdots \mathrm{S} 5$ & $\begin{array}{l}.843 \\
1.817\end{array}$ & $\begin{array}{l}1.851 \\
1.875\end{array}$ & & $\begin{array}{l}0.42 \\
0.45\end{array}$ & $\begin{array}{l}0.05 \\
0.04\end{array}$ & $\begin{array}{l}0.44 \\
0.24\end{array}$ & $\begin{array}{l}-8.1 \\
-7.2\end{array}$ & $\begin{array}{l}0.57 \\
0.61\end{array}$ & $\begin{array}{l}-0.06 \\
-0.06\end{array}$ & $\begin{array}{l}-0.09 \\
-0.08\end{array}$ \\
\hline $\mathrm{Cl} 20 \cdots \mathrm{S} 5$ & $\begin{array}{l}1.797 \\
1.795\end{array}$ & $\begin{array}{l}1.840 \\
1.833\end{array}$ & & $\begin{array}{l}0.44 \\
0.52\end{array}$ & $\begin{array}{l}0.05 \\
0.04\end{array}$ & $\begin{array}{l}1.22 \\
0.29\end{array}$ & $\begin{array}{l}-8.2 \\
-8.5 \\
\end{array}$ & $\begin{array}{l}0.58 \\
0.67\end{array}$ & $\begin{array}{l}-0.04 \\
-0.06\end{array}$ & $\begin{array}{l}-0.10 \\
-0.08 \\
\end{array}$ \\
\hline $15 \mathrm{~K}$ & & & & & & & & & & \\
\hline Intradimer & & & & & & & & & & \\
\hline $\mathrm{S} 11 \cdots \mathrm{C} 23-\mathrm{C} 15$ & $\begin{array}{l}1.730 \\
1.725\end{array}$ & $\begin{array}{l}1.518 \\
1.601\end{array}$ & $\begin{array}{l}1.811 \\
1.625\end{array}$ & $\begin{array}{l}0.74 \\
0.72\end{array}$ & $\begin{array}{l}0.10 \\
0.08\end{array}$ & $\begin{array}{l}0.42 \\
4.60\end{array}$ & $\begin{array}{l}-20.2 \\
-17.0\end{array}$ & $\begin{array}{l}1.19 \\
0.99\end{array}$ & $\begin{array}{l}-0.18 \\
-0.04\end{array}$ & $\begin{array}{l}-0.26 \\
-0.23\end{array}$ \\
\hline $\mathrm{C} 17 \cdots \mathrm{C} 2-\mathrm{C} 9^{a}$ & 1.548 & 1.710 & 1.872 & 0.69 & 0.08 & 2.23 & -15.6 & 0.93 & -0.06 & -0.18 \\
\hline $\mathrm{C} 17-\mathrm{C} 21 \cdots \mathrm{C} 9^{b}$ & 1.617 & 1.571 & 1.846 & 0.59 & 0.06 & 4.85 & -12.0 & 0.75 & -0.02 & -0.14 \\
\hline $\mathrm{Cl} 20 \cdots \mathrm{S} 5$ & $\begin{array}{l}1.718 \\
1.762\end{array}$ & $\begin{array}{l}.845 \\
1.792\end{array}$ & & $\begin{array}{l}0.52 \\
0.62\end{array}$ & $\begin{array}{l}0.06 \\
0.05\end{array}$ & $\begin{array}{l}1.61 \\
0.52\end{array}$ & $\begin{array}{l}-10.5 \\
-10.0\end{array}$ & $\begin{array}{l}0.69 \\
0.78\end{array}$ & $\begin{array}{l}-0.05 \\
-0.06\end{array}$ & $\begin{array}{l}-0.12 \\
-0.09\end{array}$ \\
\hline 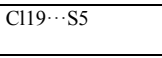 & $\begin{array}{l}1.838 \\
1.801 \\
\end{array}$ & $\begin{array}{l}1.832 \\
1.848\end{array}$ & & $\begin{array}{l}0.41 \\
0.50\end{array}$ & $\begin{array}{l}0.04 \\
0.04\end{array}$ & $\begin{array}{l}0.69 \\
0.51 \\
\end{array}$ & $\begin{array}{l}-6.7 \\
-8.1 \\
\end{array}$ & $\begin{array}{l}0.56 \\
0.66\end{array}$ & $\begin{array}{r}-0.06 \\
-0.06 \\
\end{array}$ & $\begin{array}{l}-0.10 \\
-0.09\end{array}$ \\
\hline Interdimer & & & & & & & & & & \\
\hline 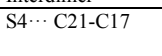 & $\begin{array}{l}1.855 \\
1.884\end{array}$ & $\begin{array}{l}.738 \\
1.875\end{array}$ & $\begin{array}{l}1.967 \\
1.718\end{array}$ & $\begin{array}{l}0.38 \\
0.44\end{array}$ & $\begin{array}{l}0.04 \\
0.04\end{array}$ & $\begin{array}{l}1.85 \\
3.99\end{array}$ & $\begin{array}{l}-6.4 \\
-7.4\end{array}$ & $\begin{array}{l}0.50 \\
0.55\end{array}$ & $\begin{array}{l}-0.03 \\
-0.02\end{array}$ & $\begin{array}{l}-0.09 \\
-0.09\end{array}$ \\
\hline $\mathrm{Cl} 25 \cdots \mathrm{S} 12$ & $\begin{array}{l}1.819 \\
1.828\end{array}$ & $\begin{array}{l}1.890 \\
1.879\end{array}$ & & $\begin{array}{l}0.43 \\
0.43\end{array}$ & $\begin{array}{l}0.04 \\
0.04\end{array}$ & $\begin{array}{l}0.88 \\
0.08\end{array}$ & $\begin{array}{l}-6.8 \\
-6.8\end{array}$ & $\begin{array}{l}0.59 \\
0.59\end{array}$ & $\begin{array}{l}-0.06 \\
-0.08\end{array}$ & $\begin{array}{l}-0.11 \\
-0.08\end{array}$ \\
\hline $\mathrm{Cl} 126 \cdots \mathrm{S} 12$ & $\begin{array}{l}1.820 \\
1.809\end{array}$ & $\begin{array}{l}1.839 \\
1.845\end{array}$ & & $\begin{array}{l}0.44 \\
0.49\end{array}$ & $\begin{array}{l}0.04 \\
0.04\end{array}$ & $\begin{array}{l}2.12 \\
0.21\end{array}$ & $\begin{array}{l}-6.5 \\
-7.9\end{array}$ & $\begin{array}{l}0.59 \\
0.64\end{array}$ & $\begin{array}{l}-0.04 \\
-0.07\end{array}$ & $\begin{array}{l}-0.11 \\
-0.08\end{array}$ \\
\hline
\end{tabular}

Table 4 Topological characteristics of the electron density at selected $(3,-1)$ interchain CPs. Same comments as Table 3.

\begin{tabular}{|c|c|c|c|c|c|c|c|c|c|}
\hline $105 \mathrm{~K}$ & d1 & $\mathrm{d} 2$ & $\nabla^{2} \rho$ & $\rho$ & $\varepsilon$ & $\mathrm{V}(\mathrm{r})$ & $\lambda_{3}$ & $\lambda_{2}$ & $\lambda_{1}$ \\
\hline $\mathrm{H} 6 \cdots \mathrm{O} 18$ & $\begin{array}{l}0.881 \\
0.878 \\
\end{array}$ & $\begin{array}{l}1.396 \\
1.404\end{array}$ & $\begin{array}{l}1.21 \\
1.08\end{array}$ & $\begin{array}{l}0.06 \\
0.09 \\
\end{array}$ & $\begin{array}{l}0.05 \\
0.02 \\
\end{array}$ & $\begin{array}{l}-16.7 \\
-20.2 \\
\end{array}$ & $\begin{array}{l}1.70 \\
1.75 \\
\end{array}$ & $\begin{array}{l}-0.24 \\
-0.33 \\
\end{array}$ & $\begin{array}{l}-0.25 \\
-0.33 \\
\end{array}$ \\
\hline $\mathrm{H} 7 \cdots \mathrm{O} 18$ & $\begin{array}{l}1.000 \\
0.971 \\
\end{array}$ & $\begin{array}{l}1.443 \\
1.453 \\
\end{array}$ & $\begin{array}{l}0.90 \\
0.88 \\
\end{array}$ & $\begin{array}{l}0.06 \\
0.06 \\
\end{array}$ & $\begin{array}{l}0.14 \\
0.04 \\
\end{array}$ & $\begin{array}{l}-13.9 \\
-15.0 \\
\end{array}$ & $\begin{array}{l}1.26 \\
1.34\end{array}$ & $\begin{array}{l}-0.17 \\
-0.22 \\
\end{array}$ & $\begin{array}{l}-0.19 \\
-0.23 \\
\end{array}$ \\
\hline $\mathrm{Cl} 20 \cdots \mathrm{S} 4$ & $\begin{array}{l}1.722 \\
1.757\end{array}$ & $\begin{array}{l}1.759 \\
1.723 \\
\end{array}$ & $\begin{array}{l}0.49 \\
0.54\end{array}$ & $\begin{array}{l}0.06 \\
0.04\end{array}$ & $\begin{array}{l}0.28 \\
0.08\end{array}$ & $\begin{array}{r}-10.2 \\
-8.5\end{array}$ & $\begin{array}{l}0.71 \\
0.72 \\
\end{array}$ & $\begin{array}{l}-0.10 \\
-0.08 \\
\end{array}$ & $\begin{array}{l}-0.12 \\
-0.09\end{array}$ \\
\hline $\mathrm{Cl} 20 \cdots \mathrm{Cl} 19$ & $\begin{array}{l}1.732 \\
1.743\end{array}$ & $\begin{array}{l}1.734 \\
1.738 \\
\end{array}$ & $\begin{array}{l}0.50 \\
0.56\end{array}$ & $\begin{array}{l}0.05 \\
0.04 \\
\end{array}$ & $\begin{array}{l}0.10 \\
0.14\end{array}$ & $\begin{array}{r}-8.8 \\
-8.6 \\
\end{array}$ & $\begin{array}{l}0.70 \\
0.77 \\
\end{array}$ & $\begin{array}{l}-0.09 \\
-0.09 \\
\end{array}$ & $\begin{array}{l}-0.10 \\
-0.11 \\
\end{array}$ \\
\hline $15 \mathrm{~K}$ & & & & & & & & & \\
\hline Short & & & & & & & & & \\
\hline $\mathrm{H} 13 \cdots \mathrm{O} 24$ & $\begin{array}{l}0.827 \\
0.813 \\
\end{array}$ & $\begin{array}{l}1.343 \\
1.346 \\
\end{array}$ & $\begin{array}{l}1.47 \\
1.36 \\
\end{array}$ & $\begin{array}{l}0.10 \\
0.11\end{array}$ & $\begin{array}{l}0.03 \\
0.01\end{array}$ & $\begin{array}{l}-26.8 \\
-29.0\end{array}$ & $\begin{array}{l}2.20 \\
2.32\end{array}$ & $\begin{array}{l}-0.36 \\
-0.48\end{array}$ & $\begin{array}{l}-0.37 \\
-0.48 \\
\end{array}$ \\
\hline H14 $\cdots \mathrm{O} 18$ & $\begin{array}{l}0.901 \\
0.888\end{array}$ & $\begin{array}{l}1.387 \\
1.389 \\
\end{array}$ & $\begin{array}{l}1.28 \\
1.17\end{array}$ & $\begin{array}{l}0.09 \\
0.09\end{array}$ & $\begin{array}{l}0.07 \\
0.06\end{array}$ & $\begin{array}{l}-22.9 \\
-21.9\end{array}$ & $\begin{array}{l}1.89 \\
1.86\end{array}$ & $\begin{array}{l}-0.3 \\
-0.33 \\
\end{array}$ & $\begin{array}{l}-0.32 \\
-0.35 \\
\end{array}$ \\
\hline $\mathrm{Cl} 20 \cdots \mathrm{S} 11$ & $\begin{array}{l}1.704 \\
1.721\end{array}$ & $\begin{array}{l}1.703 \\
1.683\end{array}$ & $\begin{array}{l}0.44 \\
0.62\end{array}$ & $\begin{array}{l}0.06 \\
0.05\end{array}$ & $\begin{array}{l}0.44 \\
0.06\end{array}$ & $\begin{array}{r}-9.7 \\
-10.0\end{array}$ & $\begin{array}{l}0.75 \\
0.85\end{array}$ & $\begin{array}{l}-0.12 \\
-0.11\end{array}$ & $\begin{array}{l}-0.18 \\
-0.12\end{array}$ \\
\hline $\mathrm{Cl} 26^{\cdots} \mathrm{Cl} 19$ & $\begin{array}{l}1.770 \\
1.747 \\
\end{array}$ & $\begin{array}{l}1.727 \\
1.753 \\
\end{array}$ & $\begin{array}{l}0.51 \\
0.54 \\
\end{array}$ & $\begin{array}{l}0.05 \\
0.04 \\
\end{array}$ & $\begin{array}{l}0.14 \\
0.15 \\
\end{array}$ & $\begin{array}{r}-8.9 \\
-8.3 \\
\end{array}$ & $\begin{array}{l}0.73 \\
0.75 \\
\end{array}$ & $\begin{array}{l}-0.11 \\
-0.09 \\
\end{array}$ & $\begin{array}{l}-0.12 \\
-0.11 \\
\end{array}$ \\
\hline Long & & & & & & & & & \\
\hline H6 $\cdots \mathrm{O} 18$ & $\begin{array}{l}0.858 \\
0.857 \\
\end{array}$ & $\begin{array}{l}1.373 \\
1.389 \\
\end{array}$ & \begin{tabular}{|l|l|}
1.28 \\
1.16
\end{tabular} & $\begin{array}{l}0.09 \\
0.09 \\
\end{array}$ & $\begin{array}{l}0.02 \\
0.03 \\
\end{array}$ & $\begin{array}{r}-22.9 \\
-22.0 \\
\end{array}$ & $\begin{array}{l}1.90 \\
1.91 \\
\end{array}$ & $\begin{array}{l}-0.30 \\
-0.37 \\
\end{array}$ & $\begin{array}{l}-0.31 \\
-0.38 \\
\end{array}$ \\
\hline $\mathrm{H} 7 \cdots \mathrm{O} 24$ & $\begin{array}{l}0.969 \\
0.935\end{array}$ & $\begin{array}{l}1.405 \\
1.425\end{array}$ & $\begin{array}{l}1.12 \\
1.02\end{array}$ & $\begin{array}{l}0.08 \\
0.07\end{array}$ & $\begin{array}{l}0.09 \\
0.08\end{array}$ & $\begin{array}{l}-19.5 \\
-16.7\end{array}$ & $\begin{array}{l}1.64 \\
1.57\end{array}$ & $\begin{array}{l}-0.25 \\
-0.26\end{array}$ & $\begin{array}{l}-0.27 \\
-0.28 \\
\end{array}$ \\
\hline $\mathrm{Cl} 26 \cdots \mathrm{S} 4$ & $\begin{array}{l}1.725 \\
1.751\end{array}$ & $\begin{array}{l}1.740 \\
1.711\end{array}$ & $\begin{array}{l}0.41 \\
0.56\end{array}$ & $\begin{array}{l}0.06 \\
0.04\end{array}$ & $\begin{array}{l}0.23 \\
0.12\end{array}$ & $\begin{array}{l}-9.5 \\
-8.9\end{array}$ & $\begin{array}{l}0.71 \\
0.75\end{array}$ & $\begin{array}{l}-0.14 \\
-0.08\end{array}$ & $\begin{array}{l}-0.17 \\
-0.09\end{array}$ \\
\hline $\mathrm{Cl} 20 \cdots \mathrm{Cl} 25$ & $\begin{array}{l}1.849 \\
1.745 \\
\end{array}$ & $\begin{array}{l}1.632 \\
1.733 \\
\end{array}$ & $\begin{array}{l}0.56 \\
0.56\end{array}$ & $\begin{array}{l}0.04 \\
0.04\end{array}$ & $\begin{array}{l}1.34 \\
0.14\end{array}$ & $\begin{array}{l}-8.0 \\
-8.7 \\
\end{array}$ & $\begin{array}{l}0.62 \\
0.78\end{array}$ & $\begin{array}{l}-0.02 \\
-0.10 \\
\end{array}$ & $\begin{array}{l}-0.04 \\
-0.11 \\
\end{array}$ \\
\hline
\end{tabular}

Table 5 Comparison between $\kappa-\mathrm{P}_{\mathrm{v}}$, multipolar and topological net charges (e) of atoms of TTF-CA at $15 \mathrm{~K}$, statistical errors are $0.02 \mathrm{e}$.

\begin{tabular}{|c|c|c|c|c|c|c|c|}
\hline TTF Atom & $\mathrm{C} 1 / \mathrm{C} 8$ & C2/C9 & $\mathrm{C} 3 / \mathrm{C} 10$ & S4/S11 & S5/S12 & H6/H13 & H7/H14 \\
\hline$\kappa-P_{v}$ & -0.26 & 0.13 & -0.24 & 0.20 & 0.30 & 0.14 & 0.06 \\
\hline $\begin{array}{l}\text { Multipolar } \\
\text { model }\end{array}$ & -0.59 & -0.23 & -0.50 & 0.38 & 0.55 & 0.38 & 0.34 \\
\hline $\begin{array}{l}\text { Topological } \\
\text { exp }\end{array}$ & -0.53 & -0.23 & -0.29 & 0.38 & 0.50 & 0.31 & 0.26 \\
\hline $\begin{array}{l}\text { Topological } \\
\text { theo }\end{array}$ & -0.14 & -0.30 & -0.13 & 0.28 & 0.33 & 0.14 & 0.13 \\
\hline CA Atom & C15/C21 & C16/C22 & C17/C23 & O18/024 & Cl19/Cl25 & $\mathrm{Cl20} / \mathrm{Cl26}$ & \\
\hline$\kappa-P_{v}$ & 0.22 & 0.23 & 0.14 & -0.42 & -0.27 & -0.23 & \\
\hline Multipolar & 0.32 & -0.04 & 0.20 & -0.44 & \begin{tabular}{l|l|}
-0.11 \\
\end{tabular} & -0.25 & \\
\hline $\begin{array}{l}\text { Topological } \\
\text { exp }\end{array}$ & 0.92 & 0.05 & 0.30 & -1.09 & -0.19 & -0.34 & \\
\hline $\begin{array}{l}\text { Topological } \\
\text { theo }\end{array}$ & 0.95 & 0.08 & 0.08 & -1.11 & -0.16 & -0.16 & \\
\hline
\end{tabular}



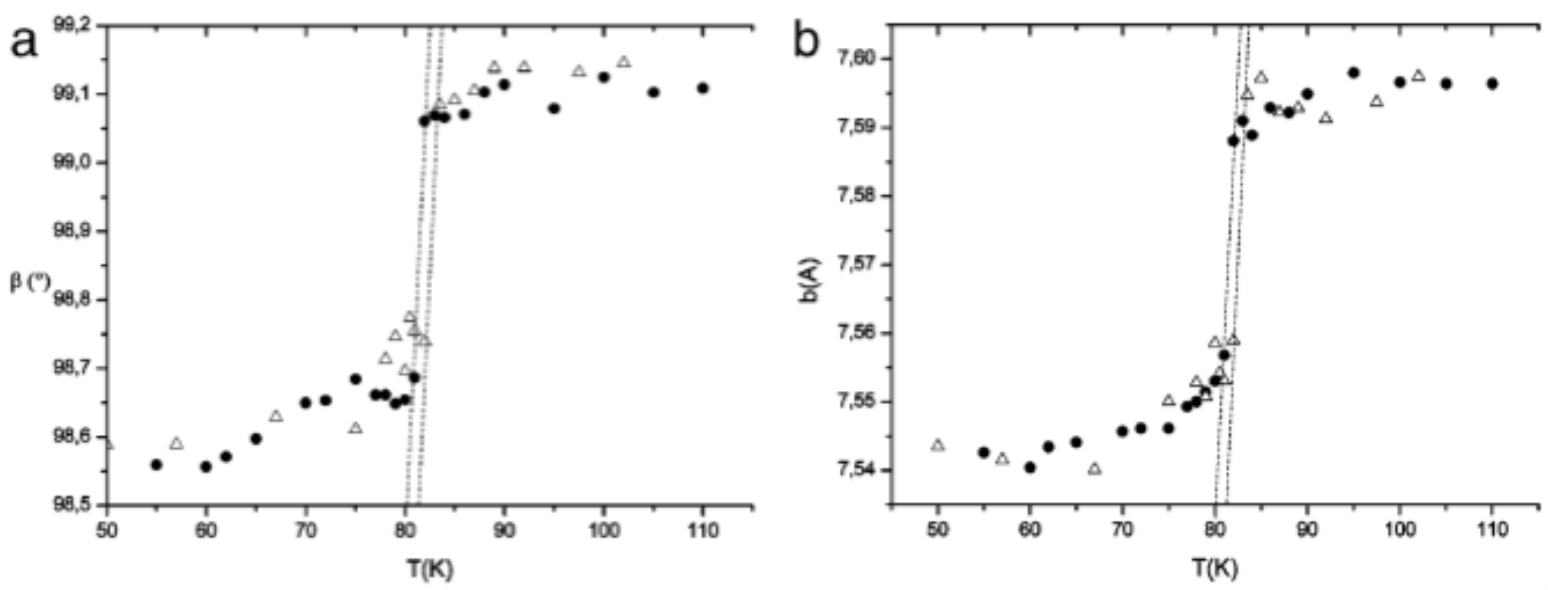

Fig. 1a: Temperature evolution of the beta angle $\left({ }^{\circ}\right)$. Cooling (circles) and warming (triangles). The standard error estimated on statistical ground is $0.02^{\circ}$.

Fig. 1b: Temperature evolution of the b parameter (Á). Cooling (circles) and warming (triangles). The standard error estimated on statistical ground is $0.001 \AA$.
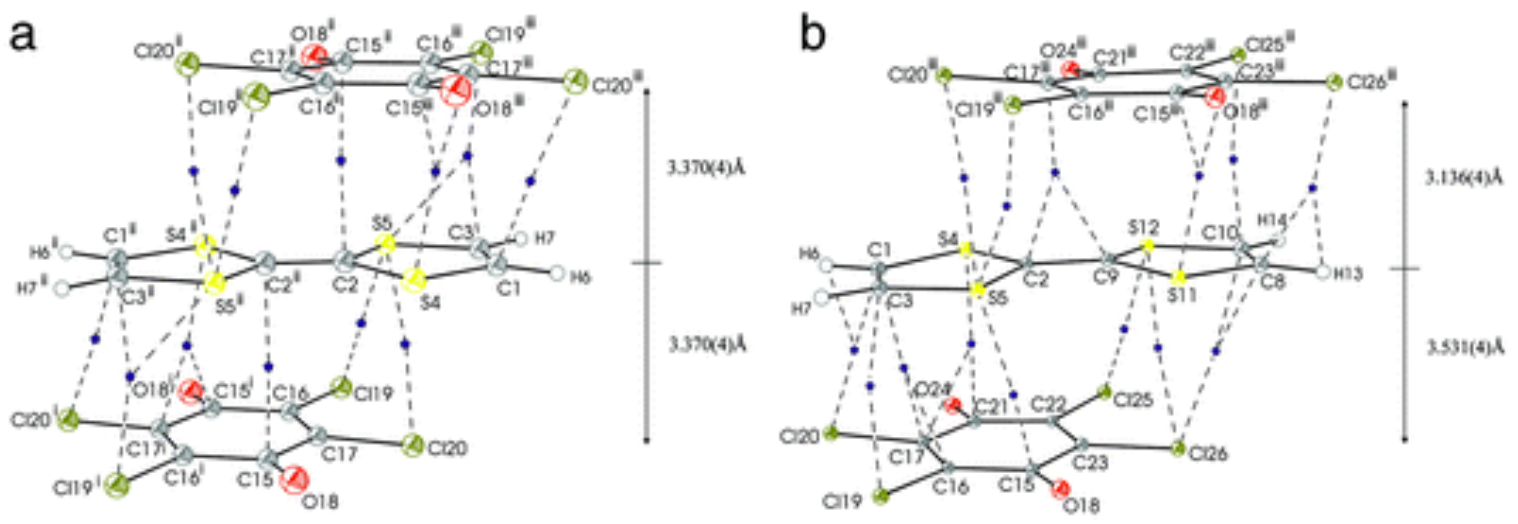

Fig. 2a: Experimental critical points associated to the strongest intrastack contacts in TTF-CA at $105 \mathrm{~K}$ and shortest distance (C2 $\cdots \mathrm{C} 15)$.

Fig. 2b: Experimental critical points associated to the strongest intrastack contacts in TTF-CA at $15 \mathrm{~K}$ and shortest intra and interdimer distances $(\mathrm{C} 9 \cdots \mathrm{C} 21$ and $\mathrm{C} 2 \cdots \mathrm{C} 15$ respectively).

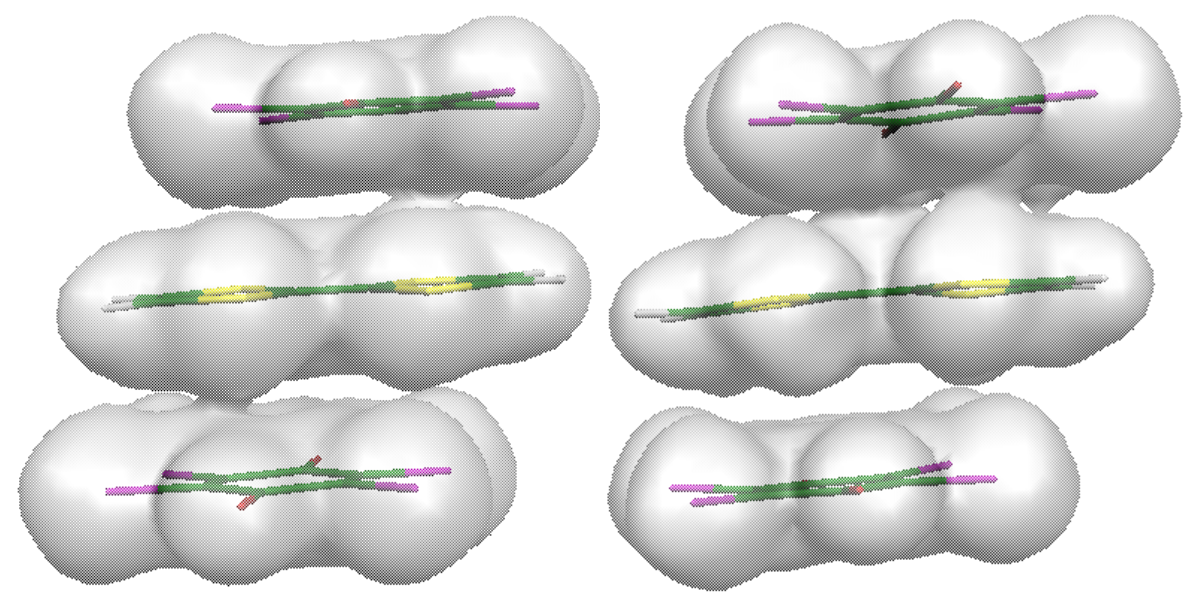

Fig. 3a: Experimental total charge density at $105 \mathrm{~K}$. Isocontours of $0.065 \mathrm{e} / \AA^{3}$.

Fig. 3b: Experimental total charge density at $15 \mathrm{~K}$. Isocontours of $0.065 \mathrm{e} / \AA^{3}$ : the dimer is clearly identified. 

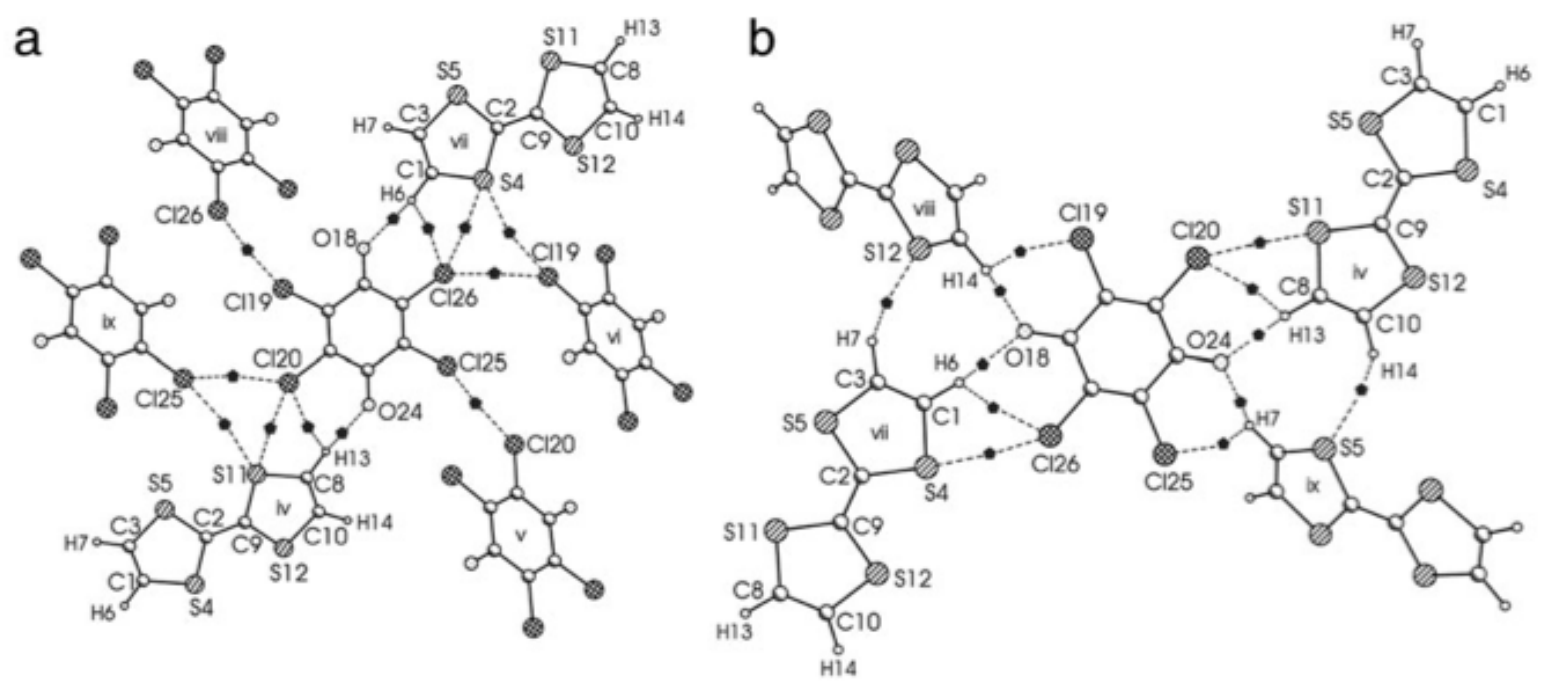

Fig. 4a: Experimental critical points associated to the strongest interstack interactions at $15 \mathrm{~K}$.

Fig. 4b: Experimental critical points around CA molecule associated to the strongest interstack interactions at $15 \mathrm{~K}$.

1A

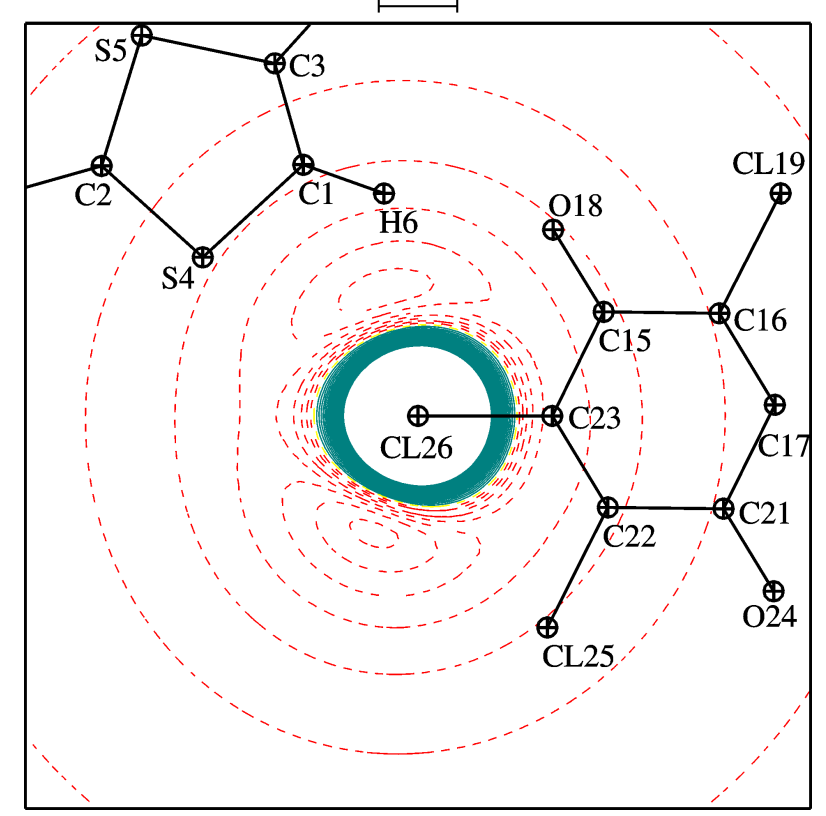

Fig. 5: Contribution of the chlorine atom to the electrostatic potential at $15 \mathrm{~K}$. Contours intervals are $0.02 \mathrm{e} / \AA \AA$. 